\title{
Galhas de insetos em restingas da região sudeste do Brasil com novos registros
}

\author{
Valéria Cid Maia ${ }^{1,2}$ \\ ${ }^{1}$ Departamento de Entomologia, Museu Nacional, Universidade Federal do Rio de Janeiro - UFRJ, \\ Quinta da Boa Vista, São Cristóvão, CEP 20940-040, Rio de Janeiro, RJ, Brazil \\ ${ }^{2}$ Autor para correspondência: Valéria Cid Maia, e-mail: maiavcid@acd.ufrj.br
}

MAIA, V.C. Insect galls from restingas of Southeastern Brazil, with new records. Biota Neotrop. 13(1): http:// www.biotaneotropica.org.br/v13n1/en/abstract?inventory+bn01613012013

\begin{abstract}
The restingas of the Southeastern region of Brazil present 476 morphotypes of insect galls found on 60 families, 131 genera, and 229 plant species. Myrtaceae, Asteraceae, and Fabaceae are the plant families with the greatest richness of galls and number of galled species. The superhost genera are Eugenia (Myrtaceae), Mikania (Asteraceae), and Myrcia (Myrtaceae). The superhost species are Guapira opposita (Nyctaginaceae), Mikania cf. biformis (Asteraceae), and six species of (Myrtaceae); Eugenia adstringens, Eugenia multiflora, Eugenia copacabanensis, Myrcia fallax, Myrciaria floribunda and Psidium cattleyanum. The galls occur on all vegetative and reprodutive plant organs, being more common on leaves. The gallers belong to Diptera, Lepidoptera, Hemiptera, Coleoptera, Thysanoptera, and Hymenoptera. Cecidomyiidae (Diptera) are the most frequent galling insects and the single group that produces galls on all plant organs, showing a strong preference for leaves. Lepidoptera are in the second place and the gallers attack leaves, stems, buds and fruits, with a strong preference for stems. Little is known about the taxonomical knowlegde of galling species ( $21 \%$ are identified at species level and $14 \%$ at genus level). The other records are in suprageneric categories. Cecidomyiidae are represented by 43 genera (about $49 \%$ of the Brazilian fauna) with 156 species (84 determined and 72 not determined), showing a good representativeness in the Southeastern region of Brazil. The most diversified genera are Clinodiplosis (31 spp.), Neolasioptera (17 spp.), Asphondylia (15 spp.), Lopesia (15 spp.), and Dasineura (13 spp.). Fifteen new gall occurrences are recorded from Cabo Frio and Paraty (RJ), and a new record of host plant is presented. Keywords: diversity, insect galls, host plant.
\end{abstract}

MAIA, V.C. Galhas de insetos em restingas da região sudeste do Brasil com novos registros. Biota Neotrop. 13(1): http://www.biotaneotropica.org.br/v13n1/pt/abstract?inventory+bn01613012013

Resumo: As restingas da região sudeste do Brasil apresentam 476 morfotipos de galhas de insetos distribuídos em 60 famílias, 131 gêneros e 229 espécies de plantas. As Myrtaceae, Asteraceae e Fabaceae destacam-se por apresentar maior riqueza de galhas e maior número de espécies galhadas. Os gêneros super-hospedeiros são Eugenia (Myrtaceae), Mikania (Asteraceae) e Myrcia (Myrtaceae). As espécies super-hospedeiras são: Guapira opposita (Nyctaginaceae), Mikania cf. biformis (Asteraceae) e seis espécies de Myrtaceae: Eugenia adstringens, Eugenia multiflora, Eugenia copacabanensis, Myrcia fallax, Myrciaria floribunda e Psidium cattleyanum. As galhas ocorrem em todos os órgãos vegetativos e reprodutivos, predominando nas folhas. Os indutores pertencem às ordens Diptera, Lepidoptera, Hemiptera, Coleoptera, Thysanoptera e Hymenoptera. Os Cecidomyiidae (Diptera) destacam-se como o principal grupo galhador e são os únicos insetos a induzir galhas em todos os órgãos vegetais, mostrando uma forte preferência por folhas. Os Lepidoptera representam o segundo grupo galhador mais diversificado em relação ao órgão vegetal atacado, induzindo galhas em folhas, caules, gemas e frutos, com forte preferência por caule. O conhecimento taxonômico das espécies galhadoras ainda é incipiente. Apenas 35\% das espécies galhadoras estão identificadas (21\% em nível de espécie e 14\% em nível de gênero). Os demais registros estão em categorias taxonômicas supragenéricas. Os Cecidomyiidae estão representados por 43 gêneros (cerca de $49 \%$ da fauna brasileira desta família) com 156 espécies ( 84 determinadas e 72 não determinadas), mostrando uma boa representatividade do grupo na região sudeste. Os gêneros mais diversificados são: Clinodiplosis (31 spp.), Neolasioptera (17 spp.), Asphondylia (15 spp.), Lopesia (15 spp.) e Dasineura (13 spp.). Quinze novas ocorrências de galhas são assinaladas para os municípios de Cabo Frio e Paraty (RJ), e uma nova espécie de planta hospedeira é registrada.

Palavras-chave: diversidade, galhas de inseto, plantas hospedeiras. 


\section{Introdução}

Galhas de insetos em restingas na região sudeste do Brasil vêm sendo investigadas desde 1985 (Monteiro et al. 1994). Trabalhos de levantamento são conhecidos para cinco municípios no estado do Rio de Janeiro (Angra dos Reis, Arraial do Cabo, Carapebus, Maricá e Rio de Janeiro), um no estado de São Paulo (Bertioga) e um no Espírito Santo (Guarapari). Em decorrência desses estudos, diversas espécies e gêneros novos de insetos galhadores vêm sendo descritos, desde então, desse ecossistema (Maia et al. 1992, Maia 1993a, 1994, 1995, 1996a, b, 2001b, 2005, 2007, 2010, Maia \& Fonseca, 2011).

Inseridas na Mata Atlântica, as restingas originalmente estendiamse desde o norte até o sul do país, por aproximadamente cinco mil quilômetros, mas atualmente encontram-se muito fragmentadas, devido principalmente à ação antrópica (Araujo \& Maciel, 1998). No estado do Rio de Janeiro, as restingas ocupam uma área de 1.200 $\mathrm{km}^{2}$ (cerca de 2,8\% do território estadual); em São Paulo, 90 km², sendo que $88 \mathrm{~km}^{2}$ desse total situam-se em uma mancha praticamente contínua na porção setentrional da Planície de Bertioga. No Espírito Santo, estendem-se por $411 \mathrm{~km}$, desde a divisa do estado com a Bahia até a divisa com o Rio de Janeiro, ocupando uma área de cerca de 31 mil hectares (Araujo \& Maciel 1998, Martins et al. 2008).

A riqueza de galhas de inseto em restingas da região sudeste vem sendo evidenciada em diversas publicações (Lima et al. 2000, Maia 2001a, Maia et al. 2008, Monteiro et al. 2004, Bregonci et al. 2010). Para o restante do litoral do Brasil, não há trabalhos de levantamento de galhas de insetos desse ecossistema. Como o conhecimento disponível encontra-se disperso na literatura, perguntas básicas sobre esse assunto carecem de respostas, tais como: 1) quantas galhas de insetos são conhecidas nas restingas da região sudeste do Brasil? 2) quantas espécies, gêneros e famílias botânicas são hospedeiras dessas galhas? 3) quais famílias de plantas comportam maior riqueza de galhas? 4) quais são os órgãos vegetais mais atacados por insetos galhadores? 5) quais ordens de insetos destacam-se como indutores de galhas? 6) existe alguma preferência pelas diferentes ordens de insetos galhadores em relação ao órgão vegetal de ocorrência da galha?

Esse trabalho se propõe a responder essas perguntas, registrando a ocorrência de galhas em outras localidades, aumentando dessa forma as informações sobre as áreas de distribuição dessas espécies indutoras, como também registrando novas associações entre galhadores e plantas hospedeiras e contribuindo para o conhecimento das galhas de insetos nas restingas da região sudeste do Brasil.

\section{Material e Métodos}

Foi realizado um levantamento bibliográfico dos artigos publicados em revistas científicas com enfoque em diversidade de galhas de insetos para a região sudeste do Brasil, bem como trabalhos de taxonomia dessas espécies galhadoras. Além dos dados retirados da literatura, a coleção de galhas do Museu Nacional/UFRJ foi examinada em busca de novos registros de localidades e de espécies de plantas hospedeiras.

Foi elaborada uma listagem por ordem alfabética das famílias botânicas com galhas, e dentro de cada família, os gêneros e espécies hospedeiras são apresentados também em ordem alfabética. As espécies não determinadas seguem após as identificadas. O número de morfotipos de galhas é indicado entre parêntesis após o nome de cada família e espécie botânica. Informações sobre a morfologia das galhas, o inseto indutor, as localidades de ocorrência e as referências são fornecidas, e os novos registros são assinalados.

Não foi possível padronizar a caracterização das galhas, em função das descrições originais não seguirem um padrão uniforme. A única informação em comum para todos os morfotipos restringe-se ao órgão vegetal atacado.

As seguintes abreviaturas de localidades foram adotadas: $\mathrm{AC}=$ Arraial do Cabo $(\mathrm{RJ}), \mathrm{BER}=$ Bertioga $(\mathrm{SP}), \mathrm{CAR}=$ Carapebus $(\mathrm{RJ}), \mathrm{CF}=$ Cabo Frio (RJ), GRU = Grumari (RJ), GUA = Guarapari (ES), IG = Ilha Grande (RJ), JU = Jurubatiba (RJ), MAR = Maricá $(\mathrm{RJ}), \mathrm{PA}=$ Paraty $(\mathrm{RJ})$.

\section{Resultados}

As restingas da região sudeste do Brasil apresentam 476 morfotipos de galhas de insetos distribuídos em 60 famílias, 131 gêneros e 229 espécies de plantas. As Myrtaceae, Asteraceae e Fabaceae destacam-se por apresentar maior riqueza de galhas, com 97, 42 e 31 morfotipos, respectivamente (Tabela 1). Estas também

Tabela 1. Distribuição do número de morfotipos de galhas de insetos, de gêneros e de espécies com galhas por família de planta hospedeira em restingas da região sudeste do Brasil.

Table 1. Distribution of the number of insect gall morphotypes, galled plant genera and species by plant families in restingas of the southeastern region of Brazil.

\begin{tabular}{lccc}
\hline Famílias de planta hospedeira & $\mathbf{N}^{\mathbf{0}}$ de morfotipos de galhas & $\mathbf{N}^{\mathbf{0}}$ de gêneros com galha & $\mathbf{N}^{\mathbf{0}}$ de espécies com galha \\
\hline ACANTHACEAE & 1 & 1 & 1 \\
ANACARDIACEAE & 4 & 3 & 3 \\
ANNONACEAE & 7 & 3 & 3 \\
APOCYNACEAE & 5 & 1 & 3 \\
AQUIFOLIACEAE & 7 & 1 & 3 \\
ARACEAE & 2 & 1 & 1 \\
ASCLEPIADACEAE & 3 & 2 & 2 \\
ASTERACEAE & $\mathbf{4 2}$ & $\mathbf{5}$ & $\mathbf{1 8}$ \\
BIGNONIACEAE & 9 & 5 & 5 \\
BORAGINACEAE & 6 & 1 & 2 \\
BURSERACEAE & 12 & 1 & 3 \\
CACTACEAE & 1 & 1 & 1 \\
CELASTRACEAE & 4 & 2 & 3 \\
CHRYSOBALANACEAE & 4 & 2 & 2 \\
CLETHRACEAE & 2 & 1 & 1 \\
\hline
\end{tabular}


Tabela 1. Continuação...

\begin{tabular}{|c|c|c|c|}
\hline Famílias de planta hospedeira & $\mathrm{N}^{0}$ de morfotipos de galhas & $\mathrm{N}^{0}$ de gêneros com galha & $\mathrm{N}^{0}$ de espécies com galha \\
\hline CLUSIACEAE & 12 & 3 & 6 \\
\hline COMMELINACEAE & 1 & 1 & 1 \\
\hline CONNARACEAE & 1 & 1 & 1 \\
\hline CONVOLVULACEAE & 1 & 1 & 1 \\
\hline CYATHEACEAE & 1 & 1 & 1 \\
\hline DILLENIACEAE & 1 & 1 & 1 \\
\hline DIOSCOREACEAE & 1 & 1 & 1 \\
\hline EBENACEAE & 1 & 1 & 1 \\
\hline ELAEOCARPACEAE & 3 & 1 & 1 \\
\hline ERYTHROXYLACEAE & 6 & 1 & 2 \\
\hline EUPHORBIACEAE & 15 & 8 & 8 \\
\hline FABACEAE & 31 & 11 & 20 \\
\hline GESNERIACEAE & 6 & 2 & 2 \\
\hline HIPPOCRATEACEAE & 1 & 1 & 1 \\
\hline LAMIACEAE & 4 & 3 & 4 \\
\hline LAURACEAE & 21 & 3 & 8 \\
\hline LORANTHACEAE & 5 & 3 & 4 \\
\hline MALPIGHIACEAE & 10 & 4 & 5 \\
\hline MELASTOMATACEAE & 28 & 7 & 15 \\
\hline MELIACEAE & 3 & 1 & 1 \\
\hline MORACEAE & 2 & 1 & 2 \\
\hline MYRSINACEAE & 5 & 1 & 3 \\
\hline MYRTACEAE & 97 & 8 & 26 \\
\hline NYCTAGINACEAE & 15 & 1 & 4 \\
\hline OCHNACEAE & 3 & 1 & 1 \\
\hline OLACACEAE & 1 & 1 & 1 \\
\hline ONAGRACEAE & 1 & 1 & 1 \\
\hline ORCHIDACEAE & 1 & 1 & 1 \\
\hline PASSIFLORACEAE & 1 & 1 & 1 \\
\hline PHYTOLACCACEAE & 1 & 1 & 1 \\
\hline PICRAMNIACEAE & 1 & 1 & 1 \\
\hline PIPERACEAE & 6 & 2 & 4 \\
\hline POACEAE & 1 & 1 & 1 \\
\hline POLYGONACEAE & 5 & 2 & 4 \\
\hline POLYPODIACEAE & 1 & 1 & 1 \\
\hline RUBIACEAE & 13 & 6 & 12 \\
\hline SAPINDACEAE & 20 & 4 & 7 \\
\hline SAPOTACEAE & 12 & 3 & 6 \\
\hline SMILACACEAE & 9 & 1 & 2 \\
\hline SOLANACEAE & 12 & 3 & 8 \\
\hline STYRACACEAE & 1 & 1 & 1 \\
\hline THEACEAE & 2 & 1 & 1 \\
\hline THYMELAEACEAE & 1 & 1 & 1 \\
\hline URTICACEAE & 1 & 1 & 1 \\
\hline VERBENACEAE & 3 & 2 & 3 \\
\hline Total & 480 & 132 & 230 \\
\hline
\end{tabular}

são as famílias botânicas com maior número de espécies galhadas (26, 18 e 20, respectivamente). Os gêneros super-hospedeiros são Eugenia L., (Myrtaceae), Mikania Willd. (Asteraceae) e Myrcia DC. ex Guill (Myrtaceae) com 45, 29 e 21 morfotipos de galhas, respectivamente. Estes gêneros são bem diversificados, com cerca de 500, 450 e 360 espécies descritas (Oliveira et al. 2005, Govaerts et al. 2008, Bremer 1994) e estão bem representados em áreas de restinga.
As espécies super-hospedeiras são: Guapira opposita (Vell.) Reitz (Nyctaginaceae) com 10 morfotipos de galha, Mikania cf. biformis DC. (Asteraceae) com oito morfotipos de galhas e seis espécies de Myrtaceae, Eugenia adstringens Cambess., E.copacabanensis Kiaersk, E. multiflora (Lam.) DC., Myrcia fallax (Rich.) DC., Myrciaria floribunda (West. ex Willdenov) Berg. e Psidium cattleyanum Sabine, com 7 morfotipos cada. 
As galhas ocorrem nos órgãos vegetativos (folhas, caules, gemas, raízes adventícias e gavinha) e reprodutivos (flores e frutos). As galhas foliares desenvolvem-se principalmente no limbo, mas também nas nervuras e pecíolo. As galhas de flor ocorrem mais frequentemente nos botões florais, mas também na inflorescência, pedúnculo e ovário. A maioria das galhas desenvolve-se em um único órgão vegetal, mas 33 morfotipos desenvolvem-se em mais de um órgão. As galhas foliares predominam com $57 \%$ do total, seguidas pelas caulinares (com cerca de 18\%) e das gemas (com aproximadamente 12\%) (Tabela 2).

Os indutores pertencem a seis ordens de insetos: Diptera, Lepidoptera, Hemiptera, Coleoptera, Thysanoptera e Hymenoptera. Os Cecidomyiidae (Diptera) destacam-se como o principal grupo galhador, sendo responsáveis pela indução de 288 morfotipos (61\% do total). Ainda na ordem Diptera, tem-se registro de um único morfotipo de galha induzido por Tephritidae. Os Lepidoptera aparecem em segundo lugar, com uma porcentagem muito inferior a dos Cecidomyiidae (3\%), seguidos pelos Hemiptera, com 2,7\% do total (Tabela 3).

Os cecidomiídeos são os únicos insetos a induzir galhas em todos os órgãos vegetais, e mostram uma forte preferência por folhas (cerca de $60 \%$ do total dos morfotipos). A ordem Lepidoptera representa o segundo grupo galhador mais diversificado em relação ao órgão vegetal atacado, induzindo galhas em folhas, caules, gemas e frutos, com forte preferência por caule (cerca de 60\%). Coleoptera e Hymenoptera induzem galhas apenas em dois órgãos: folhas e caules, mas como o número de morfotipos é muito baixo (4 para cada ordem),

Tabela 2. Distribuição do número de morfotipos de galhas de insetos por órgão vegetal em restingas da região sudeste do Brasil.

Table 2. Distribution of the number of insect gall morphotypes by plant organs in restingas of the southeastern region of Brazil.

\begin{tabular}{lc}
\hline \multicolumn{1}{c}{ Órgão vegetal } & $\mathbf{N}^{0}$. de galhas \\
\hline folha & 273 \\
$\quad$ limbo & 235 \\
$\quad$ nervura & 29 \\
pecíolo & 09 \\
caule & 85 \\
gema & 58 \\
flor & 20 \\
$\quad$ botão floral & 11 \\
$\quad$ ovário & 02 \\
$\quad$ pnflorescência & 05 \\
pedúnculo floral & 02 \\
raiz adventícia & 08 \\
gavinha & 02 \\
caule e gema & 02 \\
caule e nervura & 06 \\
caule e folha & 03 \\
gema e folha & 08 \\
caule, gema e nervura & 02 \\
caule, gema, pecíolo & 01 \\
caule, pecíolo e nervura & 01 \\
caule, nervura e gavinha & 06 \\
nervura, pecíolo e gavinha & 01 \\
\hline
\end{tabular}

a preferência dessas ordens não é discutida, bem como para Hemiptera e Thysanoptera, que induzem galhas apenas em folhas (Tabela 4).

A família Cecidomyiidae ocorre em 49 famílias de plantas hospedeiras (cerca de $81 \%$ do total de famílias atacadas); Lepidoptera em 11, Hemiptera em 7, Coleoptera e igualmente Hymenoptera em 3, e Thysanoptera em apenas uma única família (Tabela 5). Sabese que na região Neotropical, galhas de Lepidoptera, Hemiptera, Coleoptera, Thysanoptera ocorrem em 22, 37, 14 e 7 famílias botânicas, respectivamente (Maia \& Oliveira 2004, Maia 2006). Para Cecidomyiidae e Hymenoptera, não há dados compilados em relação às famílias de plantas hospedeiras nesta região zoogeográfica.

O conhecimento taxonômico das espécies galhadoras ainda é rudimentar. Apenas 100 morfotipos de galhas $(21 \%$ do total dos morfotipos registrados) têm a espécie galhadora identificada. Desse montante, 98 espécies pertencem à família Cecidomyiidae (Diptera), uma espécie pertence a Psyllidae (Hemiptera) e uma a Curculionidae (Coleoptera). Para Lepidoptera, Hymenoptera e Thysanoptera, não há registros em nível de espécie. Sessenta e seis morfotipos têm o galhador identificado em nível de gênero (cerca de 14\%), todos incluídos na família Cecidomyiidae. Para os demais morfotipos, a identificação do indutor está em categorias taxonômicas supragenéricas. Esses dados evidenciam como o conhecimento das espécies galhadoras ainda é escasso, e como se faz necessária a atuação de mais taxonomistas nessa área.

Os cecidomiídeos estão representados nas restingas da região sudeste do Brasil por 43 gêneros (em todo o Brasil por 88 gêneros), o que equivale a cerca de $49 \%$ da fauna brasileira. Ao todo, somam-se 156 espécies ( 84 determinadas e 72 não determinadas), mostrando uma boa representatividade da família nesta região. Os gêneros mais diversificados nesse ecossistema são: Clinodiplosis Kieffer, 1894 (com 31 espécies), Neolasioptera Felt, 1908 (com 17 espécies), Asphondylia Loew, 1850 e Lopesia Rübsaamen, 1908, (ambos com 15 espécies) e Dasineura Rondani, 1840 (com 13 espécies), como pode ser verificado na Tabela 6 .

Clinodiplosis é um gênero cosmopolita bastante diversificado, com 102 espécies descritas, 17 das quais assinaladas para o Brasil (Toma \& Maia 2012). Em restingas, está representado por 31 espécies, mas a maioria delas (25) não está determinada. Segundo Gagné (2010), na Europa, grande parte das espécies deste gênero são micófagas, já no Novo Mundo muitas são fitófagas e algumas na região Neotropical causam galhas complexas. Nas restingas investigadas, as espécies de Clinodiplosis também apresentam hábito variado, incluindo fitófagos de vida livre (três espécies), inquilinos de galhas (uma espécie), indutores de galhas simples (17 espécies) e

Tabela 3. Distribuição do número de morfotipos de galhas de insetos por ordem de insetos em restingas da região sudeste do Brasil.

Table 3. Distribution of the number of insect gall morphotypes by insect orders in restingas of the southeastern region of Brazil.

\begin{tabular}{lc}
\hline Ordem do inseto galhador & $\begin{array}{c}\text { No. de morfotipos de galhas } \\
(\mathbf{n}=\mathbf{4 7 6})\end{array}$ \\
\hline Diptera & 289 \\
Cecidomyiidae & 288 \\
Tephritidae & 01 \\
Lepidoptera & 16 \\
Hemiptera & 13 \\
Coleoptera & 06 \\
Thysanoptera & 04 \\
Hymenoptera & 04 \\
Não determinada & 144
\end{tabular}


Tabela 4. Distribuição do número de morfotipos de galhas por ordem de inseto galhador e órgão vegetal atacado em restingas da região sudeste do Brasil. Table 4. Distribution of the number of gall morphotypes by plant organs and insect orders in restingas of the southeastern region of Brazil.

\begin{tabular}{lcccccc}
\hline \multirow{2}{*}{ Órgão vegetal } & \multicolumn{7}{c}{ Ordem de inseto galhador } \\
\cline { 2 - 7 } & $\begin{array}{c}\text { Diptera } \\
(\mathbf{n = 2 8 9})\end{array}$ & $\begin{array}{c}\text { Lepidoptera } \\
(\mathbf{n}=\mathbf{1 6})\end{array}$ & $\begin{array}{c}\text { Coleoptera } \\
(\mathbf{n = 6})\end{array}$ & $\begin{array}{c}\text { Hemiptera } \\
(\mathbf{n}=\mathbf{1 3})\end{array}$ & $\begin{array}{c}\text { Thysanoptera } \\
(\mathbf{n}=\mathbf{4})\end{array}$ & $\begin{array}{c}\text { Hymenoptera } \\
(\mathbf{n}=\mathbf{4})\end{array}$ \\
\hline Caule & 30 & 10 & 03 & 0 & 0 & 03 \\
Folha & 170 & 02 & 03 & 13 & 04 & 01 \\
Gema & 42 & 01 & 0 & 0 & 0 & 0 \\
Flor & 18 & 0 & 0 & 0 & 0 & 0 \\
Fruto & 05 & 01 & 0 & 0 & 0 & 0 \\
Raiz & 02 & 0 & 0 & 0 & 0 & 0 \\
Gavinha & 01 & 0 & 0 & 0 & 0 & 0 \\
Caule e folha & 13 & 01 & 0 & 0 & 0 & 0 \\
Caule e gema & 05 & 01 & 0 & 0 & 0 & 0 \\
Caule, gema e folha & 02 & 0 & 0 & 0 & 0 & 0 \\
Caule, gavinha e folha & 01 & 0 & 0 & 0 & 0 & 0 \\
\hline
\end{tabular}

de galhas complexas (10 espécies). A maioria (cerca de 55\%) induz a formação de galhas simples caracterizadas pelo dobramento da folha inteira ou pelo enrolamento total ou marginal da folha, ou ainda por um espessamento do pecíolo, nervura ou caule, concordando com as informações de Gagné (2010). As galhas complexas por sua vez são induzidas nas folhas $(n=3)$ ou nas gemas $(n=7)$.

Neolasioptera é um gênero de distribuição mundial bastante diversificado, com 134 espécies conhecidas, das quais apenas sete são registradas para o Brasil. Nesse estudo, verificou-se a ocorrência de 17 espécies desse gênero, duas determinadas e 15 não determinadas (Tabela 6), 16 induzindo galhas simples e apenas uma induzindo galhas complexas. A maioria das galhas simples $(n=12)$ ocorre em caule, nervura, pecíolo, gavinha ou raiz adventícia, corroborando o que já foi observado para o gênero nas outras regiões zoogeográficas (Gagné 2010).

Asphondylia também é um gênero amplamente distribuído e muito diversificado, com 289 espécies descritas no mundo, 22 das quais com registro no Brasil. Nesse estudo, foi verificada a ocorrência de 15 espécies, sendo oito determinadas e sete não. Muitas espécies de Asphondylia induzem galhas em flores ou botões florais, essa alta freqüência foi enfatizada por Gagné (2010), e é confirmada nesse estudo, onde seis espécies ocorrem nesse órgão, cinco em folhas, quatro em caule e uma única nas gemas.

O gênero Lopesia possui ampla distribuição geográfica, ocorrendo nas regiões Neártica, Neotropical, Afrotropical e Australásia, mas é um gênero bem menos diversificado comparativamente aos supracitados, com apenas 18 espécies conhecidas e distribuição principalmente Neotropical (Maia \& Silva 2011). No Brasil, tem-se registro de 15 espécies, o mesmo número encontrado nesse estudo, porém dessas 15 espécies, quatro permanecem não identificadas. Nenhuma preferência por órgão vegetal é referida em literatura. Nesse estudo, observa-se uma forte preferência por folhas $(73 \%)$, com 12 espécies induzindo galhas nesse órgão, duas nas gemas e apenas uma em caule.

Dasineura é o gênero mais diversificado de Cecidomyiidae com mais de 460 espécies e também cosmopolita, no Brasil representado por apenas nove espécies descritas (Gagné 2010). Nas restingas, 13 espécies estão assinaladas, seis delas não determinadas. A maioria das espécies desse gênero, segundo Gagné (2010), vive livremente em flores ou induz galhas caracterizadas pelo enrolamento da margem foliar. Esse padrão não é observado nas restingas do sudeste do Brasil. Nesse estudo, nove espécies induzem galhas simples e quatro galhas complexas. Apenas três enrolamentos marginais são registrados (cerca de $23 \%$ do total). Com relação ao órgão vegetal, nota-se uma acentuada preferência por folhas (cerca de $85 \%$ ); os demais morfotipos ocorrem em gemas.

Os gêneros Bruggmannia Tavares 1906 e Stephomyia Tavares 1916 também apresentam uma boa representatividade nas restingas investigadas. Bruggmannia é conhecido por 19 espécies, todas neotropicais e indutoras de galhas principalmente em Nyctaginaceae (Gagné 2010). Nesse estudo, Bruggmannia está representado por sete espécies (quatro determinadas e três não determinadas), todas induzindo galhas em Nyctaginaceae, corroborando o conhecimento prévio do gênero.

Stephomyia também é um gênero exclusivamente Neotropical, com sete espécies descritas indutoras de galhas em Myrtaceae (Gagné 2010). Nas restingas do sudeste do Brasil, tem-se registro de seis espécies de Stephomyia (5 determinadas e 1 não determinada), igualmente associadas a Myrtaceae.

Seis outros gêneros (Alycaulus Rübsaamen, 1916; Bruggmanniella Tavares, 1909; Contarinia Rondani, 1860; Meunieriella Kieffer, 1909; Resseliella Seitner, 1906 e Schizomyia Kieffer, 1889) de Cecidomyiidae incluem espécies não determinadas, totalizando 72. Essas espécies não puderam ser identificadas por estarem representadas por apenas uma fase do ciclo evolutivo e/ou sexo (feminino/masculino). Considerando-se a alta especificidade dos Cecidomyiidae em relação ao morfotipo de galha e espécie de planta hospedeira, pode-se afirmar que as espécies não determinadas são provavelmente novas. Chama ainda a atenção a grande quantidade de espécies que já foram descritas para restinga $(\mathrm{n}=71)$, mostrando como o conhecimento da fauna desse ecossistema é importante para o conhecimento da fauna do Brasil.

Quinze novos registros de ocorrência de galhas são assinalados para os municípios de Cabo Frio e Paraty, ambos situados no estado do Rio de Janeiro, ampliando a distribuição geográfica das espécies indutoras e uma nova espécie de planta hospedeira, Croton compressus Lam., é registrada.

Como as restingas do estado do Rio de Janeiro vêm sendo mais intensamente investigadas que comparativamente com as de São Paulo e do Espírito Santo, tanto espacialmente como temporalmente, 
Maia, V.C.

Tabela 5. Distribuição do número de morfotipos de galhas por ordem de inseto galhador e família de planta em restingas da região sudeste do Brasil.

Table 5. Distribution of the number of insect gall morphotypes by insect orders and plant families in restingas of the southeastern region of Brazil.

\begin{tabular}{|c|c|c|c|c|c|c|}
\hline & $\begin{array}{c}\text { Diptera } \\
(\mathrm{n}=\mathbf{2 8 9})\end{array}$ & $\begin{array}{l}\text { Lepidoptera } \\
\quad(\mathrm{n}=16)\end{array}$ & $\begin{array}{c}\text { Hemiptera } \\
(\mathrm{n}=13)\end{array}$ & $\begin{array}{c}\text { Coleoptera } \\
(\mathrm{n}=6)\end{array}$ & $\begin{array}{c}\text { Hymenoptera. } \\
(\mathrm{n}=4)\end{array}$ & $\begin{array}{l}\text { Thysanoptera } \\
(n=4)\end{array}$ \\
\hline Acanthaceae & 01 & 0 & 0 & 0 & 0 & 0 \\
\hline Anacardiaceae & 01 & 01 & 02 & 0 & 0 & 0 \\
\hline Annonaceae & 02 & 0 & 0 & 0 & 0 & 0 \\
\hline Apocynaceae & 01 & 0 & 02 & 0 & 0 & 0 \\
\hline Aquifoliaceae & 07 & 0 & 0 & 0 & 0 & 0 \\
\hline Araceae & 01 & 0 & 0 & 0 & 01 & 0 \\
\hline Asclepiadaceae & 03 & 0 & 0 & 0 & 0 & 0 \\
\hline Asteraceae & 31 & 01 & 0 & 0 & 0 & 0 \\
\hline Bignoniaceae & 07 & 0 & 0 & 0 & 0 & 0 \\
\hline Boraginaceae & 04 & 01 & 0 & 0 & 0 & 0 \\
\hline Burseraceae & 10 & 0 & 02 & 0 & 0 & 0 \\
\hline Cactaceae & 01 & 0 & 0 & 0 & 0 & 0 \\
\hline Celastraceae & 04 & 0 & 0 & 0 & 0 & 0 \\
\hline Chrysobalanaceae & 03 & 0 & 0 & 0 & 0 & 0 \\
\hline Clethraceae & 02 & 0 & 0 & 0 & 0 & 0 \\
\hline Clusiaceae & 08 & 02 & 0 & 0 & 0 & 0 \\
\hline Commelinaceae & 01 & 0 & 0 & 0 & 0 & 0 \\
\hline Convolvulaceae & 01 & 0 & 0 & 0 & 0 & 0 \\
\hline Ebenaceae & 01 & 0 & 0 & 01 & 0 & 0 \\
\hline Elaeocarpaceae & 02 & 0 & 0 & 0 & 0 & 0 \\
\hline Erythroxylaceae & 06 & 0 & 0 & 0 & 0 & 0 \\
\hline Euphorbiaceae & 08 & 1 & 01 & 0 & 0 & 0 \\
\hline Fabaceae & 23 & 0 & 0 & 01 & 0 & 0 \\
\hline Gesneriaceae & 01 & 01 & 0 & 0 & 0 & 0 \\
\hline Hippocrateaceae & 0 & 0 & 0 & 01 & 0 & 0 \\
\hline Lamiaceae & 02 & 0 & 0 & 0 & 0 & 0 \\
\hline Lauraceae & 05 & 0 & 03 & 0 & 0 & 0 \\
\hline Loranthaceae & 04 & 0 & 0 & 0 & 0 & 0 \\
\hline Malpighiaceae & 05 & 02 & 0 & 0 & 0 & 0 \\
\hline Melastomataceae & 09 & 03 & 0 & 01 & 0 & 0 \\
\hline Meliaceae & 03 & 0 & 0 & 0 & 0 & 0 \\
\hline Moraceae & 02 & 0 & 0 & 0 & 0 & 0 \\
\hline Myrsinaceae & 02 & 03 & 0 & 0 & 0 & 0 \\
\hline Myrtaceae & 60 & 0 & 01 & 02 & 02 & 04 \\
\hline Nyctaginaceae & 10 & 0 & 0 & 0 & 01 & 0 \\
\hline Ochnaceae & 02 & 0 & 0 & 0 & 0 & 0 \\
\hline Olacaceae & 01 & 0 & 0 & 0 & 0 & 0 \\
\hline Onagraceae & 01 & 0 & 0 & 0 & 0 & 0 \\
\hline Passifloraceae & 01 & 0 & 0 & 0 & 0 & 0 \\
\hline Phytolaccaceae & 01 & 0 & 0 & 0 & 0 & 0 \\
\hline Piperaceae & 03 & 0 & 0 & 0 & 0 & 0 \\
\hline Polygonaceae & 02 & 0 & 0 & 0 & 0 & 0 \\
\hline Polypodiaceae & 01 & 0 & 0 & 0 & 0 & 0 \\
\hline Rubiaceae & 07 & 0 & 0 & 0 & 0 & 0 \\
\hline Sapindaceae & 14 & 01 & 0 & 0 & 0 & 0 \\
\hline Sapotaceae & 08 & 0 & 0 & 0 & 0 & 0 \\
\hline Smilacaceae & 05 & 0 & 02 & 0 & 0 & 0 \\
\hline Solanaceae & 08 & 0 & 0 & 0 & 0 & 0 \\
\hline Theaceae & 02 & 0 & 0 & 0 & 0 & 0 \\
\hline Verbenaceae & 02 & 0 & 0 & 0 & 0 & 0 \\
\hline
\end{tabular}


Tabela 6. Distribuição do número de espécies de Cecidomyiidae (Diptera) no mundo, no Brasil e em restingas da região sudeste do Brasil por gêneros. Table 6. Distribution of the species number of Cecidomyiidae (Diptera) in the world, Brazil and restingas of the Southeastern region of Brazil per genus.

\begin{tabular}{|c|c|c|c|c|}
\hline \multirow[t]{2}{*}{ Gênero de Cecidomyiidae } & \multirow{2}{*}{$\begin{array}{l}\text { No. de spp. } \\
\text { Mundo }\end{array}$} & \multirow{2}{*}{$\begin{array}{l}\text { No. de spp. } \\
\text { Brasil }\end{array}$} & \multicolumn{2}{|c|}{$\begin{array}{c}\text { No. de spp. } \\
\text { Restingas }(n=156)\end{array}$} \\
\hline & & & Det. $(n=83)$ & Não det. $(n=73)$ \\
\hline Alycaulus Rübsaamen, 1916 & 03 & 02 & 1 & 2 \\
\hline Arrabidaeamyia Maia, 2001 & 1 & 1 & 1 & 0 \\
\hline Asphondylia Loew, 1850 & 289 & 22 & 8 & 7 \\
\hline Bruggmannia Tavares, 1906 & 19 & 13 & 4 & 3 \\
\hline Bruggmanniella Tavares, 1909 & 10 & 6 & 2 & 1 \\
\hline Burseramyia Möhn, 1960 & 2 & 1 & 1 & 0 \\
\hline Clinodiplosis Kieffer, 1894 & 102 & 17 & 6 & 25 \\
\hline Clusiamyia Maia, 1997 & 2 & 2 & 2 & 0 \\
\hline Contarinia Rondani, 1860 & 311 & 2 & 1 & 2 \\
\hline Cordiamyia Maia, 1996 & 1 & 1 & 1 & 0 \\
\hline Costadiplosis Viceconte \& Maia, 2009 & 1 & 1 & 1 & 0 \\
\hline Dactylodiplosis Rübsaamen, 1916 & 3 & 2 & 2 & 0 \\
\hline Dasineura Rondani, 1840 & 467 & 9 & 7 & 6 \\
\hline Epihormomyia Felt, 1915 & 1 & 1 & 1 & 0 \\
\hline $\begin{array}{l}\text { Eugeniamyia Maia,Mendonça \& } \\
\text { Romanowski } 1997\end{array}$ & 1 & 1 & 1 & 0 \\
\hline Guareamyia Maia, 2007 & 1 & 1 & 1 & 0 \\
\hline Iatrophobia Rübsaamen, 1916 & 1 & 1 & 1 & 0 \\
\hline Jorgenseniella Maia, 2005 & 1 & 1 & 1 & 0 \\
\hline Lestodiplosis Kieffer, 1894 & 182 & 2 & 1 & 0 \\
\hline Liodiplosis Gagné, 2001 & 3 & 3 & 3 & 0 \\
\hline Lopesia Rübsaamen, 1908 & 18 & 15 & 11 & 4 \\
\hline Manilkaramyia Maia, 2001 & 1 & 1 & 1 & 0 \\
\hline Mayteniella Maia, 2001 & 1 & 1 & 1 & 0 \\
\hline Meunieriella Kieffer, 1909 & 21 & 3 & 0 & 1 \\
\hline Mikaniadiplosis Gagné, 2001 & 1 & 1 & 1 & 0 \\
\hline Myrciamyia Maia, 1996 & 1 & 1 & 1 & 0 \\
\hline Myrciariamyia Maia, 1995 & 1 & 1 & 1 & 0 \\
\hline Neolasioptera Felt, 1908 & 134 & 7 & 2 & 15 \\
\hline Neomitranthella Maia, 1996 & 1 & 1 & 1 & 0 \\
\hline Parazalepidota Maia, 2001 & 1 & 1 & 1 & 0 \\
\hline Paulliniamyia Maia, 2001 & 1 & 1 & 1 & 0 \\
\hline Perasphondylia Möhn, 1960 & 2 & 2 & 1 & 0 \\
\hline Pisphondylia Möhn, 1960 & 2 & 1 & 1 & 0 \\
\hline Primadiplosis Maia, 2011 & 1 & 1 & 1 & 0 \\
\hline Proasphondylia Felt, 1915 & 3 & 3 & 2 & 0 \\
\hline Resseliella Seitner, 1906 & 53 & 0 & 0 & 1 \\
\hline Schismatodiplosis Rübsaamen, 1916 & 1 & 1 & 1 & 0 \\
\hline Schizomyia Kieffer, 1889 & 53 & 6 & 3 & 1 \\
\hline Smilasioptera Möhn, 1975 & 1 & 1 & 1 & 0 \\
\hline Sphaeramyia Maia, 2007 & 1 & 1 & 1 & 0 \\
\hline Stephomyia Tavares, 1916 & 7 & 6 & 5 & 1 \\
\hline Trotteria Kieffer, 1902 & 23 & 1 & 1 & 2 \\
\hline Youngomyia Felt, 1908 & 6 & 1 & 1 & 0 \\
\hline
\end{tabular}


não serão feitas comparações entre a diversidade e composição da guilda dos galhadores e das galhas dessas localidades.

Abaixo segue a listagem das plantas hospedeiras e caracterização das galhas de insetos:

$$
\text { Acanthaceae }(\mathrm{n}=1)
$$

Avicennia schaueriana Stapf \& Leechm. ex Moldenke $(\mathrm{n}=1)$

Folha. Galha globóide. Indutor: Cecidomyiidae. Localidades: BER e CF (novo registro). Referência: Maia et al. (2008).

$$
\text { Anacardiaceae }(\mathrm{n}=4)
$$

Atronium sp. $(\mathrm{n}=1)$

Folha. Galha ovóide, Indutor: Hemiptera. Inquilino: Clinodiplosis sp. (Cecidomyiidae), Localidade: MAR. Referência: Maia (2001a).

Schinnus terebinthifolius Raddi $(\mathrm{n}=2)$

Folha. Galha: concavidade. Indutor: Calophya terebinthifolii Burckhardt \& Basset, 2000 (Psyllidae, Hemiptera). Localidades: PA (novo registro), IG e MAR. Referências: Maia \& Oliveira (2010) e Monteiro et al. (1994).

Caule. Galha: espessamento. Indutor: Lepidoptera. Localidades: BER, GRU e CF (novo registro). Referências: Oliveira \& Maia (2005) e Maia et al. (2008).

Tapirira guianensis Aubl. $(\mathrm{n}=1)$

Folha. Galha cônica. Indutor: Cecidomyiidae. Localidade: BER. Referência: Maia et al. (2008).

$$
\text { Annonaceae }(\mathrm{n}=7)
$$

Guatteria hilariana Schltdl. $(\mathrm{n}=2)$

Caule. Galha: espessamento fusiforme multilocular. Indutor: não determinado Localidade: BER. Referência: Maia et al. (2008).

Folha. Galha globóide. Indutor: não determinado. Localidade: BER. Referência: Maia et al. (2008).

Rollinia sericea R. E. Fr. $(\mathrm{n}=3)$

Folha. Galha parenquimática. Indutor: não determinado. Localidade: BER. Referência: Maia et al. (2008).

Pecíolo. Galha: espessamento fusiforme. Indutor: não determinado. Localidade: BER. Referência: Maia et al. (2008).

Botão floral. Galha ovóide. Indutor: Clinodiplosis sp. (Cecidomyiidae). Localidade: BER. Referência: Maia et al. (2008).

Forsteronia leptocarpa (Hook. \& Arn). A. DC $(\mathrm{n}=2)$

Folha. Galha cônica. Indutor: Cecidomyiidae. Localidade: BER. Referência: Maia et al. (2008).

Nervura central. Galha: espessamento fusiforme. Indutor: não determinado. Localidade: BER. Referência: Maia et al. (2008). Apocynaceae $(\mathrm{n}=5)$

Aspidosperma parvifolium A. CD. $(\mathrm{n}=2)$

Folha. Galha parenquimática, circular, verde. Indutor: Psyllidae (Hemiptera). Localidade: GRU. Referência: Oliveira \& Maia (2005).

Botão floral. Galha ovóide, verde. Indutor: Cecidomyiidae. Localidade: GRU. Referência: Oliveira \& Maia (2005).

Aspidosperma pyricollum Muell. Arg. $(\mathrm{n}=1)$

Folha. Galha circular. Indutor: Psyllidae (Hemiptera). Localidades: IG e MAR. Referências: Maia \& Oliveira (2010) e Monteiro et al. (1994).
Apocynaceae não determinada $(\mathrm{n}=2)$

Folha. Galha cônica, verde. Indutor não determinado. Localidade: GUA. Referência: Bregonci et al. (2010).

Folha. Galha: enrolamento da borda, verde. Indutor não determinado. Localidade: GUA. Referência: Bregonci et al. (2010).

$$
\text { Aquifoliaceae }(n=7)
$$

Ilex pseudobuxus Reissek $(\mathrm{n}=2)$

Gema. Galha achatada, verde. Indutor: Cecidomyiidae.

Localidade: BER. Referência: Maia et al. (2008).

Caule. Galha: espessamento globoso. Indutor: Cecidomyiidae.

Localidade: BER. Referência: Maia et al. (2008).

Ilex theezans Mart. $(\mathrm{n}=3)$

Folha. Galha parenquimática, verde, unilocular. Indutor:

Cecidomyiidae. Localidade: BER. Referência: Maia et al. (2008).

Folha. Galha bursiforme, verde. Indutor: Cecidomyiidae.

Localidade: BER. Referência: Maia et al. (2008).

Caule. Galha: espessamento globóide. Indutor: Cecidomyiidae.

Localidade: BER. Referência: Maia et al. (2008).

Ilex sp. $(\mathrm{n}=2)$

Gema. Galha esférica, verde, glabra. Indutor: Cecidomyiidae.

Localidade: IG. Referência: Maia \& Oliveira (2010).

Folha. Galha redonda, verde, glabra. Indutor: Cecidomyiidae. Localidade: GUA. Referência: Bregonci et al. (2010).

$$
\text { Araceae }(\mathrm{n}=2)
$$

Philodendron appendiculatum Nadruz \& Mayo $(\mathrm{n}=2)$

Folha. Galha elíptica, amarelada, unilocular. Indutor: Hymenoptera. Localidades: BER e PA (novo registro). Referência: Maia et al. (2008).

Raiz. Galha ovóide, unilocular. Indutor: Cecidomyiidae. Localidade: BER. Referência: Maia et al. (2008).

$$
\text { Asclepiadaceae }(\mathrm{n}=3)
$$

Peplonia asteria (Veil.) Font. \& Schw. $(\mathrm{n}=2)$

Botão floral. Galha ovóide. Indutor: Asphondylia peploniae Maia 2001 (Cecidomyiidae). Localidades: CAR e JU. Referências: Maia (2001a, b) e Monteiro et al. (2004).

Folha. Galha: borda enrolada Indutor: Clinodiplosis sp. (Cecidomyiidae). Localidades: CAR e JU. Referências: Maia (2001a, b) e Monteiro et al. (2004).

Oxypetalum banksii $(\mathrm{n}=1)$

Botão floral. Galha ovóide. Indutor: Asphondylia sp. (Cecidomyiidae). Localidades: MAR, AC e JU Referências: Monteiro et al. (1994, 2004).

$$
\text { Asteraceae }(\mathrm{n}=42)
$$

Achyrocline satureioides (Lam.) DC. $(\mathrm{n}=1)$

Caule ou gema. Galha: espessamento fusiforme. Indutor não determinado. Localidade: BER. Referência: Maia et al. (2008).

Baccharis conyzoides DC. $(\mathrm{n}=1)$

Folha. Galha preta, globosa, unilocular. Indutor: Asphondylia sp. (Cecidomyiidae). Localidade: BER. Referência: Maia et al. (2008)

Baccharis dracunculifolia DC. $(\mathrm{n}=1)$

Botão floral. Galha ovóide. Indutor não determinado. Localidade: BER. Referência: Maia et al. (2008).

Baccharis singularis (Vell.) G. M. Barroso $(\mathrm{n}=2)$ 
Gema. Galha verde, ovóide com folha saindo apicalmente. Indutor: Neolasioptera sp. (Cecidomyiidae). Localidade: BER. Referência: Maia et al. (2008).

Nervura ou caule. Galha: espessamento fusiforme. Indutor não determinado. Localidade: BER. Referência: Maia et al. (2008).

Baccharis speciosa DC. $(\mathrm{n}=2)$

Caule. Galha globóide, unilocular, lateral. Indutor não determinado. Localidade: BER. Referência: Maia et al. (2008).

Caule ou gema. Galha: espessamento fusiforme. Indutor: Alycauliini (Cecidomyiidae). Localidade: BER. Referência: Maia et al. (2008).

Baccharis sp. $(\mathrm{n}=1)$

Folha. Galha fusiforme, verde, glabra. Indutor não determinado. Localidade: IG. Referência: Maia \& Oliveira (2010).

Mikania argyreiae DC. $(\mathrm{n}=2)$

Caule. Galha: espessamento fusiforme. Indutor: Cecidomyiidae.

Localidade: BER. Referência: Maia et al. (2008).

Folha. Galha globóide. Indutor não determinado. Localidade: BER. Referência: Maia et al. (2008).

Mikania cf. biformis DC. $(\mathrm{n}=8)$

Folha ou caule. Galha globosa suculenta. Indutor: Liodiplosis spherica Gagné, 2001 (Cecidomyiidae). Localidade: BER. Referência: Maia et al. (2008).

Caule, pecíolo ou nervura. Galha: espessamento fusiforme. Indutor: Mikaniadiplosis annulipes Gagné, 2001 (Cecidomyiidae). Localidade: BER. Referência: Maia et al. (2008).

Caule. Galha: espessamento fusiforme. Indutor: Asphondylia moehni Skuhravá,1989 (Cecidomyiidae). Localidade: BER. Referência: Maia et al. (2008).

Folha ou caule. Galha cônica. Indutor: Liodiplosis conica Gagné, 2001 (Cecidomyiidae). Localidade: BER. Referência: Maia et al. (2008).

Nervura central. Galha: espessamento discreto. Indutor: Alycaulus globulus Gagné, 2001 (Cecidomyiidae). Localidade: BER. Referência: Maia et al. (2008).

Nervura ou pecíolo. Galha: espessamento acentuado. Indutor: Asphondylia glomeratae Gagné, 2001 (Cecidomyiidae).

Localidade: BER. Referência: Maia et al. (2008).

Folha. Galha cilíndrica, delgada. Indutor: Liodiplosis cylindrica Gagné, 2001 (Cecidomyiidae). Localidade: BER. Referência: Maia et al. (2008).

Gema. Galha ovóide. Indutor: Perasphondylia mikaniae Gagné, 2001 (Cecidomyiidae). Localidade: BER. Referência: Maia et al. (2008).

Mikania cf. glomerata Spreng. $(\mathrm{n}=2)$

Pecíolo. Galha: espessamento fusiforme. Indutor: Clinodiplosis sp. (Cecidomyiidae). Localidade: BER. Referência: Maia et al. (2008).

Folha. Galha globosa. Indutor: Liodiplosis spherica (Cecidomyiidae). Localidade: BER. Referência: Maia et al. (2008).

Mikania glomerata Spreng. $(\mathrm{n}=6)$

Nervura central. Galha: espessamento discreto. Indutor: Alycaulus globulus Gagné, 2001 (Cecidomyiidae). Localidade: GRU. Referência: Oliveira \& Maia (2005).

Caule. Galha: espessamento fusiforme. Indutor: Asphondylia moehni Skuhravá,1989 (Cecidomyiidae). Localidade: GRU. Referência: Oliveira \& Maia (2005).
Folha ou caule. Galha cônica. Indutor: Liodiplosis conica Gagné, 2001 (Cecidomyiidae). Localidade: GRU. Referência: Oliveira \& Maia (2005).

Folha. Galha globosa. Indutor: Liodiplosis spherica (Cecidomyiidae). Localidade: PA (novo registro).

Folha. Galha cilíndrica, delgada. Indutor: Liodiplosis cylindrica Gagné, 2001 (Cecidomyiidae). Localidade: PA (novo registro).

Gema. Galha ovóide. Indutor: Perasphondylia mikaniae Gagné, 2001 (Cecidomyiidae). Localidade: PA (novo registro).

Mikania hoehnei Robinson $(\mathrm{n}=2)$

Folha. Galha: dobramento ao longo da nervura central, verde. Indutor: Clinodiplosis sp. (Cecidomyiidae). Localidade: MAR. Referência: Maia (2001a).

Caule. Galha: espessamento ovóide. Indutor: Alycaulus sp. (Cecidomyiidae). Localidade: MAR.e AC. Referências: Maia (2001a) e Monteiro et al. (1994).

Mikania involucrata Hook. \& Arn. $(\mathrm{n}=2)$

Caule. Galha: espessamento irregular. Indutor: Cecidomyiidae. Localidade: BER. Referência: Maia et al. (2008).

Nervura. Galha: espessamento fusiforme. Indutor não determinado. Localidade: BER. Referência: Maia et al. (2008).

Mikania cf. micrantha Kunth. $(\mathrm{n}=1)$

Nervura central ou pecíolo. Galha: espessamento fusiforme. Indutor: Alycaulus trilobatus Möhn, 1964 (Cecidomyiidae). Localidade: BER. Referência: Maia et al. (2008).

Mikania ternata (Vell.) B. L. Rob. $(\mathrm{n}=2)$

Gema. Galha esférica. Indutor: Lopesiini (Cecidomyiidae). Localidade: BER. Referência: Maia et al. (2008).

Caule. Galha: espessamento fusiforme. Indutor: Lepidoptera. Localidade: BER. Referência: Maia et al. (2008).

Mikania sp. $(\mathrm{n}=4)$

Folha ou caule. Galha globosa suculenta. Indutor: Liodiplosis spherica Gagné, 2001 (Cecidomyiidae). Localidade: IG. Referência: Maia \& Oliveira (2010).

Folha. Galha cilíndrica, delgada. Indutor: Liodiplosis cylindrica Gagné, 2001 (Cecidomyiidae). Localidade: IG. Referência: Maia \& Oliveira (2010).

Folha ou caule. Galha cônica. Indutor: Liodiplosis conica Gagné, 2001 (Cecidomyiidae). Localidade: IG. Referência: Maia \& Oliveira (2010).

Caule, pecíolo ou nervura. Galha: espessamento fusiforme. Indutor: Mikaniadiplosis annulipes Gagné, 2001 (Cecidomyiidae). Localidade: IG. Referência: Oliveira \& Maia (2008).

Piptocarpha cf. cinerea Baker $(\mathrm{n}=2)$

Caule, gema ou nervura. Galha ovóide, unilocular. Indutor: Cecidomyiidii (Cecidomyiidae). Localidade: BER. Referência: Maia et al. (2008).

Pecíolo, gema ou caule. Galha globosa. Indutor: Asphondylia sp. (Cecidomyiidae). Localidade: BER. Referência: Maia et al. (2008).

Vernonia beyrichii Less. $(\mathrm{n}=1)$

Caule ou gema. Galha: espessamento ovóide. Indutor: Tephritidae (Diptera). Localidade: BER. Referência: Maia et al. (2008).

Vernonia rufogrisea St. Hill. $(\mathrm{n}=2)$ 
Pecíolo. Galha esférica. Indutor: Asphondylia sp. (Cecidomyiidae). Localidades: CAR e JU. Referência: Monteiro et al. (2004).

Gema. Galha esférica, pubescente, amarelada. Indutor: Asphondylia sp. (Cecidomyiidae). Localidade: CAR. Referência: Maia (2001a).

$$
\text { Bignoniaceae }(\mathrm{n}=9)
$$

Anemopaegma chamberlaynii (Sims) Bureau \& K. Schum. $(\mathrm{n}=1)$

Caule, pecíolo ou nervura. Galha: espessamento fusiforme. Indutor: Neolasioptera sp. (Cecidomyiidae). Localidade: BER. Referência: Maia et al. (2008).

Fridericia conjugata (Veil.) Mart. ( $\mathrm{n}=3)$ ( = Arrabidaea conjugata)

Folha. Galha cônica. Indutor: Arrabidaeamyia serrata Maia 2001 (Cecidomyiidae). Localidades: GRU, MAR, AC, CAR e JU. Referências: Maia 2001a, b, Monteiro et al. (1994, 2004) e Oliveira \& Maia (2005).

Caule, nervura central e gavinha. Galha: espessamento fusiforme. Indutor: Neolasioptera sp. (Cecidomyiidae). Localidades: GRU, AR, CAR e JU. Referências: Maia (2001a), Monteiro et al. (1994, 2004) e Oliveira \& Maia (2005).

Ovário. Galha esférica, glabra, roxa. Indutor: Cecidomyiinae. Localidade: MAR. Referência: Maia (2001a).

Lundia virginalis DC. var. nitidula (DC.) A. H. Gentry $(\mathrm{n}=1)$

Larvas livres no caule. Clinodiplosis sp.(Cecidomyiidae). Localidade: BER. Referência: Maia et al. (2008).

Parabignonia unguiculata (Vell.) A. H. Gentry $(\mathrm{n}=3)$

Folha. Galha parenquimática, unilocular. Indutor: Cecidomyiidae. Localidade: BER. Referência: Maia et al. (2008).

Caule. Galha: espessamento fusiforme. Indutor não determinado. Localidade: BER. Referência: Maia et al. (2008).

Gavinha. Galha: espessamento fusiforme. Indutor não determinado. Localidade: BER. Referência: Maia et al. (2008).

Tabebuia sp. $(\mathrm{n}=1)$

Folha. Galha: intumescimento e enrolamento da folha. Indutor: Clinodiplosis sp. (Cecidomyiidae). Localidade: BER. Referência: Maia et al. (2008).

$$
\text { Boraginaceae }(n=6)
$$

Cordia curassavica (Jacq.) Roem. \& Schult. $(\mathrm{n}=4)$

Folha. Galha globosa, pilosa. Indutor: Cordiamyia globosa Maia, 1996 (Cecidomyiidae). Localidades: BER, MAR, AC, CAR, JU e GUA. Referências: Bregonci et al. (2010), Maia (1996a, 2001a), Maia et al. (2008) e Monteiro et al. (1994, 2004).

Botão floral. Galha ovóide, pilosa. Indutor: Asphondylia cfr. cordiae Möhn, 1959 (Cecidomyiidae). Localidades: BER, MAR, CF (novo registro), CAR e JU. Referências: Maia (2001a), Maia et al. (2008) e Monteiro et al. (2004).

Caule. Galha: espessamento fusiforme, unilocular. Indutor: Lepidoptera. Localidades: BER e CF (novo registro). Referência: Maia et al. (2008).

Folha. Galha alongada, irregular na largura, unilocular. Indutor: Lopesiini (Cecidomyiidae). Localidades: BER, MAR e CF (novo registro). Referências: Maia (2001a) e Maia et al. (2008).

Cordia sellowiana Cham. $(\mathrm{n}=2)$

Folha. Galha esférica, pilosa, marrom, unilocular. Indutor: Cecidomyiidae. Localidade: BER. Referência: Maia et al. (2008).

Folha. Galha parenquimática. Indutor não determinado. Localidade: BER. Referência: Maia et al. (2008).
Burseraceae $(n=12)$

Protium brasiliense (Spr.) Engl. $(\mathrm{n}=2)$

Folha. Galha cônica, glabra. Indutor: Cecidomyiidi (Cecidomyiidae). Localidade: MAR. Referência: Maia (2001a).

Folha. Enrolamento da borda. Indutor: Lopesia maricaensis Rodrigues \& Maia (2009) (Cecidomyiidae). Localidade: MAR. Referências: Maia (2001a) e Rodrigues \& Maia (2010).

Protium heptaphyllum (Aublet.) March ( $\mathrm{n}=5$ )

Folha. Galha epidérmica. Indutor: Psyllidae (Hemiptera). Localidades: MAR, AC e JU. Referência: Monteiro et al. (1994, 2004).

Folha. Galha: enrolamento da borda. Indutor: Lopesia similis Maia, 2004 (Cecidomyiidae). Localidades: CAR e JU. Referências: Maia (2001a), Narahara et al. (2004) e Monteiro et al. (2004).

Folha. Galha esférica. Indutor: Dactylodiplosis heptaphylli Maia, 2004 (Cecidomyiidae). Localidades: CAR e JU. Referências: Maia (2001a), Narahara et al. (2004) e Monteiro et al. (2004)

Folha. Galha ovóide. Indutor: Cecidomyiidi (Cecidomyiidae). Localidade: CAR. Referência: Maia (2001a).

Folha. Galha: enrolamento da borda. Indutor: Cecidomyiidi (Cecidomyiidae). Localidade: CAR. Referência: Maia (2001a).

Protium icicariba (DC.) March. $(\mathrm{n}=5)$

Folha. Galha cônica. Indutor: Dactylodiplosis icicaribae Maia, 2002 (Cecidomyiidae). Localidades: CAR e JU. Referências: Maia (2001a), Maia et al. (2002a, 2004) e Monteiro et al. (2004).

Folha. Galha: enrolamento da borda. Indutor: Lopesia simplex Maia, 2002 (Cecidomyiidae). Localidades: CAR, JU e GUA. Referências: Bregonci et al. (2010), Maia (2001a), Maia et al. (2002a) e Monteiro et al. (2004).

Folha. Galha epidérmica. Indutor: Psyllidae (Hemiptera). Localidades: JU e GUA. Referências: Bregonci et al. (2010) e Monteiro et al. (2004).

Fruto. Galha não perceptível. Indutor: Cecidomyiinae. Localidades: CAR e JU. Referências: Maia (2001a), Monteiro et al. (2004).

Folha. Galha ovóide. Indutor: Cecidomyiinae. Localidade: CAR. Referência: Maia (2001a).

$$
\text { Cactaceae }(\mathrm{n}=1)
$$

Selenicereus setaceus $(\mathrm{SO})$ Berg ( = Cereus setaceus) $(\mathrm{n}=1)$

Caule. Espessamento ovóide. Indutor: Neolasioptera cerei Rübsaamen, 1905 (Cecidomyiidae). Localidades: IG, CAR e JU. Referências: Maia (2001a), Maia \& Oliveira (2010) e Monteiro et al. (2004).

$$
\text { Celastraceae }(\mathrm{n}=4)
$$

Elachyptera micrantha (Cambess.) A. C. Sm. $(\mathrm{n}=1)$

Gema ou folha. Galha sulcada. Indutor: Cecidomyiidae. Localidade: BER. Referência: Maia et al. (2008).

Maytenus obtusifolia Mart. var. obovata Mart. $(\mathrm{n}=2)$

Folha. Galha circular. Indutor: Mayeniella distincta Maia, 2001 (Cecidomyiidae). Localidades: GRU, MAR e AC. Referências: Maia (2001a, b), Monteiro et al. (1994, 2004) e Oliveira \& Maia (2005).

Fruto. Galha externamente não perceptível. Indutor: Bruggmanniella maytenuse (Maia \& Couri, 1992) (Cecidomyiidae). Localidade: MAR. Referências: Maia et al. (1992), Maia (1999, 2001a) e Monteiro et al. (1994, 2004). 
Maytenus robusta Reissek $(\mathrm{n}=1)$

Folha. Galha globóide, unilocular. Indutor: Cecidomyiidae. Localidade: BER. Referência: Maia et al. (2008).

Chrysobalanaceae $(\mathrm{n}=4)$

Couepia ovalifolia (Schott) Benth. $(\mathrm{n}=2)$

Folha. Galha circular. Indutor: Dasineura conepiae Maia, 2001 (Cecidomyiidae). Localidades: MAR e GUA. Referências: Bregonci et al. (2010) e Maia (2001a, b).

Folha. Galha: enrolamento da borda. Indutor: Lopesia marginalis Maia, 2001 (Cecidomyiidae). Localidade: MAR. Referência: (Maia 2001a, b).

Licania nitida Hook. f. $(\mathrm{n}=2)$

Caule. Galha: espessamento fusiforme. Indutor não determinado. Localidade: BER. Referência: Maia et al. (2008).

Nervuras laterais. Galha: espessamento discreto na superfície na superior e protuberante na superfície inferior. Indutor: Lopesia sp. (Cecidomyiidae). Localidade: BER. Referência: Maia et al. (2008).

$$
\text { Clethraceae }(\mathrm{n}=2)
$$

Clethra scabra Pers. var. laevigata (Meisn.) Sleumer $(\mathrm{n}=2)$

Caule. Galha: espessamento irregular, unilocular. Indutor: Cecidomyiidae. Localidade: BER. Referência: Maia et al. (2008).

Gema. Galha lenhosa, verde, estriada, com uma folha projetando-se do ápice. Indutor: Clinodiplosis sp. (Cecidomyiidae). Localidade: BER. Referência: Maia et al. (2008).

$$
\text { Clusiaceae }(\mathrm{n}=12)
$$

Calophyllum brasiliense Cambess. $(\mathrm{n}=5)$

Folha. Galha globosa. Indutor: Lopesia conspicua Maia, 2003 (Cecidomyiidae). Localidade: JU. Referências: Madeira et al. (2002) e Monteiro et al. (2004).

Folha. Galha parenquimática, elíptica, unilocular. Indutor: Lopesia elliptica Maia, 2003 (Cecidomyiidae). Localidades: BER e JU. Referências: Madeira et al. (2002), Maia et al. (2008) e Monteiro et al. (2004).

Folha. Galha linear, projetando-se verticalmente, unilocular. Indutor: Lopesia linearis Maia, 2003 (Cecidomyiidae). Localidades: BER e JU. Referências: Madeira et al. (2002), Maia et al. (2008) e Monteiro et al. (2004).

Caule. Galha: espessamento globoso, unilocular. Indutor: Lopesia caulinaris Maia, 2003 (Cecidomyiidae). Localidades: BER e JU. Referências: Madeira et al. (2002), Maia et al. (2008) e Monteiro et al. (2004).

Gema apical. Galha globóide, unilocular. Indutor: Contarinia gemmae Maia, 2003 (Cecidomyiidae). Localidades: BER e JU. Referências: Madeira et al. (2002), Maia et al. (2008) e Monteiro et al. (2004).

Clusia criuva Cambess. subsp. parviflora Vesque $(\mathrm{n}=1)$

Folha. Galha parenquimática, elíptica, unilocular. Indutor: Lepidoptera. Localidade: BER. Referência: Maia et al. (2008).

Clusia hilariana Schltdl. $(\mathrm{n}=2)$

Folha. Galha circular Indutor: Clusiamyia granulosa Maia, 2001 (Cecidomyiidae) Localidades: CAR, JU e SET. Referências: Bregonci et al. (2010), Maia (2001a, b) e Monteiro et al. (2004).

Folha. Galha: enrolamento da borda. Indutor não determinado. Localidade: GUA. Referência: Bregonci et al. (2010).

Clusia fluminensis Tr. \& PI. $(\mathrm{n}=2)$
Folha. Galha circular. Indutor: Parazalepidota clusiae Maia 2001 (Cecidomyiidae). Localidades: GRU e MAR. Referências: (Maia 2001a, b) e Oliveira \& Maia (2005).

Folha. Galha parenquimática, linear. Indutor: Lepidoptera. Localidade: MAR. Referência: Monteiro et al.(1994).

Clusia lanceolata Camb. $(\mathrm{n}=1)$

Folha. Galha esférica, suculenta. Indutor: Clusiamyia nitida Maia, 1996 (Cecidomyiidae). Localidades: MAR e AC. Referências: Maia (1996b, 2001a) e Monteiro et al. (1994).

Garcinia gardneriana (Planch. \& Triana) Zappi $(\mathrm{n}=1)$

Caule. Galha gongilóide, castanha, rígida e glabra. Indutor não determinado. Localidade: BERT. Referência: Lima et al. (2000). Commelinaceae $(\mathrm{n}=1)$

Commelina diffusa Burm. f. $(\mathrm{n}=1)$

Caule. Galha: espessamento fusiforme. Indutor: Clinodiplosis sp. (Cecidomyiidae). Localidade: BER. Referência: Maia et al. (2008).

$$
\text { Connaraceae }(\mathrm{n}=1)
$$

Connarus rostratus (Vell.) L. B. SM. $(\mathrm{n}=1)$

Gema. Galha botuliforme, castanha, rígida, glabra. Indutor não determinado. Localidade: BER. Referência: Lima et al. (2000). Convolvulaceae $(\mathrm{n}=1)$

Jacquemontia holosericea (Weinman) O’Donell $(\mathrm{n}=1)$

Botão floral. Galha externamente não perceptível. Indutor. Schizomyia santosi Maia \& Araújo, 2009 (Cecidomyiidae). Localidade: MAR. Referências: Maia \& Araújo (2009) e Maia (2001a).

$$
\text { Cyatheaceae (Pterydophyta) }(\mathrm{n}=1)
$$

Cyathea sp. $(\mathrm{n}=1)$

Folha. Galha parenquimática, verde. Indutor não determinado. Localidade: BER. Referência: Maia et al. (2008). Dilleniaceae $(\mathrm{n}=1)$

Doliocarpus glomeratus Eichler $(\mathrm{n}=1)$

Caule. Galha: espessamento fusiforme. Indutor não determinado. Localidade: BER. Referência: Maia et al. (2008). Dioscoreaceae $(\mathrm{n}=1)$

Dioscorea monadelpha (Kunth) Griseb. $(\mathrm{n}=1)$

Pecíolo. Galha: espessamento fusiforme. Indutor não determinado. Localidade: BER. Referência: Maia et al. (2008). Ebenaceae $(\mathrm{n}=1)$

Diospyros brasiliensis Mart. ex. Miq. $(\mathrm{n}=1)$

Folha. Galha: intumescimento e enrolamento da borda. Indutor: Curculionidae (Coleoptera). Localidade: BER. Referência: Maia et al. (2008).

$$
\text { Elaeocarpaceae }(\mathrm{n}=3)
$$

Sloanea guianensis (Aubl.) Benth. $(\mathrm{n}=3)$

Folha. Galha parenquimática, unilocular. Indutor: Lasiopteridi (Cecidomyiidae). Localidade: BER. Referência: Maia et al. (2008).

Folha. Galha: borda enrolada. Indutor: Clinodiplosis sp. (Cecidomyiidae). Localidade: BER. Referência: Maia et al. (2008).

Gemas laterais. Galha cônica, unilocular. Indutor não determinado. Localidade: BER. Referência: Maia et al. (2008). Erythroxylaceae $(n=6)$ 
Erythroxylum amplifolium (Mart.) O. E. Schulz $(\mathrm{n}=1)$

Gema. Galha cônica, unilocular. Indutor: Lopesia sp. (Cecidomyiidae). Localidade: BER. Referência: Maia et al. (2008).

Erythroxylum ovalifolium Peyr. $(\mathrm{n}=5)$

Folha. Galha triangular. Indutor: Dasineura ovalifoliae Maia \& Fernandes, 2011 (Cecidomyiidae). Localidades: GRU MAR, CAR e JU. Referências: Maia (2001a), Oliveira \& Maia (2005), Maia \& Fernandes (2011) e Monteiro et al. (1994, 2004).

Folha. Galha: enrolamento da folha jovem. Indutor: Clinodiplosis sp. (Cecidomyiidae). Localidades: IG, MAR, CAR e JU. Referências: Maia (2001a), Maia \& Oliveira (2010) e Monteiro et al. (2004).

Gema. Galha cônica. Indutor: Lopesia erythroxyli Rodrigues \& Maia (2010) (Cecidomyiidae). Localidades: IG, GRU, MAR, AC, CAR e JU. Referências: Maia (2001a), Maia \& Oliveira 2010, Monteiro et al. (1994, 2004), Oliveira \& Maia (2005) e Rodrigues \& Maia (2010).

Botão floral. Galha externamente não perceptível. Indutor: Asphondylia sp. (Cecidomyiidae). Localidades: GRU, MAR, CAR e JU. Referências: Maia (2001a), Oliveira \& Maia (2005) e Monteiro et al. (2004).

Fruto. Galha ovóide, marrom. Indutor: Cecidomyiidae. Localidade: GRU. Referência: Oliveira \& Maia (2005).

$$
\text { Euphorbiaceae }(\mathrm{n}=15)
$$

Alchornea triplinervia (Spreng.) Müll. Arg. $(\mathrm{n}=1)$

Caule. Galha: espessamento fusiforme, plurilocular. Indutor: Cecidomyiidae (Diptera). Localidade: BER. Referência: Maia et al. (2008).

Chaetocarpus myrsinites $(\mathrm{n}=2)$

Folha. Galha redonda, verde ou marrom, glabra. Indutor não determinado. Localidade: GUA. Referência: Bregonci et al. (2010).

Folha. Galha: enrolamento da borda, marrom, glabro. Indutor: Hemiptera. Localidade: GUA. Referência: Bregonci et al. (2010).

Croton compressus Lam. $(\mathrm{n}=1)$

Caule. Galha: espessamento caulinar, fusiforme, verdeamarelado, glabro e unilocular. Indutor: Lepidoptera. Localidade: CF. Novo registro de planta hospedeira.

Dalechampia leandrii Baill. $(\mathrm{n}=1)$

Gema. Galha complexa, formando um emaranhado. Indutor: Schizomyiina (Cecidomyiidae). Localidades: GRU e BER. Referências: Maia et al. (2008) e Maia \& Oliveira (2010).

Maprounea guianensis Aubl. $(\mathrm{n}=1)$

Folha. Galha globóide, verde, crassa e glabra. Indutor não determinado. Localidade: BER. Referência: Lima et al. (2000).

Manihot sp. $(\mathrm{n}=1)$

Folha. Galha cilíndrica, unilocular. Indutor: Iatrophobia brasiliensis Rübsaamen, 1916 (Cecidomyiidae). Localidade: BER. Referência: Maia et al. (2008).

Pera glabrata (Schott) Poepp. ex Baill. $(\mathrm{n}=5)$

Nervura central ou caule. Galha: espessamento fusiforme. Indutor não determinado. Localidade: BER. Referência: Maia et al. (2008).
Gemas apicais e laterais. Galha ovóide com projeções apicais filiformes, unilocular. Indutor não determinado. Localidade: BER. Referência: Maia et al. (2008).

Gema. Galha ovóide, agregada. Indutor: Cecidomyiidae. Localidade: BER. Referência: Maia et al. (2008).

Gema. Galha globóide, lenhosa. Indutor: Cecidomyiidae. Localidade: BER. Referência: Maia et al. (2008).

Folha. Galha cônica, unilocular. Indutor não determinado. Localidade: BER. Referência: Maia et al. (2008).

Sebastiania glandulosa (Mart.) Pax. $(\mathrm{n}=3)$

Gema. Galha cônica. Indutor: Clinodiplosis conica Oliveira \& Maia, 2008 (Ceidomyiidae).. Localidades: MAR, CAR e JU. Referências: Maia (2001a), Monteiro et al. (2004) e Oliveira \& Maia (2008).

Gema. Galha esférica. Indutor: Schizomyia spherica Maia \& Oliveira, 2007 (Cecidomyiidae). Localidades: MAR, CAR e JU. Referências: Maia (2001a), Monteiro et al. (2004) e Maia \& Oliveira (2007).

Folha. Galha: enrolamento da borda. Indutor: Dasineura sp. (Cecidomyiidae). Localidades: MAR, CAR e JU. Referências: Maia (2001a) e Monteiro et al. (2004). Fabaceae $(\mathrm{n}=31)$

Abarema brachystachya (DC.) Barneby \& J. W. Grimes $(\mathrm{n}=1)$

Folha. Galha formada por intumescimento e enrolamento da borda. Indutor: Cecidomyiidae. Localidade: BER. Referência: Maia et al. (2008).

Andira fraxinifolia Benth. $(\mathrm{n}=3)$

Folha. Galha vermiforme, unilocular. Indutor: Cecidomyiidi. Localidade: BER. Referência: Maia et al. (2008).

Folha. Galha globosa. Indutor: Asphondyliina (Cecidomyiidae). Localidade: BER. Referência: Maia et al. (2008).

Caule. Galha: espessamento. Indutor: Curculionidae (Coleoptera). Localidade: BER. Referência: Maia et al. (2008).

Andira nitida Mart. $(\mathrm{n}=3)$

Folha. Galha globosa, verde, glabra. Indutor não determinado. Localidade: GUA. Referência: Bregonci et al. (2010).

Folha. Galha circular, verde, glabra. Indutor: Cecidomyiidae. Localidade: GUA. Referência: Bregonci et al. (2010).

Folha. Galha: enrolamento marginal, verde, glabra. Indutor: Cecidomyiidae. Localidade: GUA. Referência: Bregonci et al. (2010).

Dalbergia ecastophylla L. Taub. $(\mathrm{n}=1)$

Folha. Galha discóide. Indutor: Lopesia grandis Maia, 2001 (Cecidomyiidae). Localidades: IG, MAR, CAR e JU. Referências: Maia (2001a, b), Maia \& Oliveira (2010) e Monteiro et al. (2004).

Dalbergia frutescens (Vell.) Britton $(\mathrm{n}=1)$

Folha. Galha discóide, unilocular. Indutor: Lopesia grandis Maia, 2001 (Cecidomyiidae). Localidade: BER. Referência: Maia et al. (2008).

Dalbergia sampaioana Kuhlm. \& Hoehne $(n=1)$

Caule. Galha: espessamento fusiforme. Indutor não determinado. Localidade: BER. Referência: Maia et al. (2008).

Dalbergia sp. $(\mathrm{n}=1)$

Caule. Galha: espessamento espiralado. Indutor não determinado. Localidade: BER. Referência: Maia et al. (2008).

Desmodium adscendens (Sw.) DC. $(\mathrm{n}=1)$ 
Caule. Galha: espessamento fusiforme. Indutor não determinado. Localidade: BER. Referência: Maia et al. (2008).

Inga edulis Mart. $(\mathrm{n}=4)$

Nervura foliar. Galha globóide. Indutor: Neolasioptera sp. (Cecidomyiidae). Localidade: BER. Referência: Maia et al. (2008).

Folha. Galha elíptica, amarela. Indutor não determinado. Localidade: BER. Referência: Maia et al. (2008).

Nervura foliar. Galha espessamento conspícuo. Indutor não determinado. Localidade: BER. Referência: Maia et al. (2008).

Nervura foliar. Espessamento discreto, parenquimóide. Indutor não determinado. Localidade: BER. Referência: Maia et al. (2008).

Inga laurina $(\mathrm{Sw}$.$) Willd (\mathrm{n}=2)$

Nervura central da folha. Galha espessamento fusiforme. Indutor: Neolasioptera sp. (Cecidomyiidae). Localidade: MAR. Referência: Maia et al. (2002b).

Folha. Galha cilíndrica. Indutor: Meunieriella sp. (Cecidomyiidae). Localidade: MAR. Referência: Maia et al. (2002b).

Inga maritima Benth. $(\mathrm{n}=1)$

Caule, pecíolo e nervura central. Galha: espessamento fusiforme. Indutor: Neolasioptera sp. (Cecidomyiidae). Localidades: GRU e MAR. Referências: Maia (2001a) e Oliveira \& Maia (2005).

Inga sellowiana Benth. $(\mathrm{n}=2)$

Nervura foliar. Galha: espessamento fusiforme. Indutor: Lasiopteridi (Cecidomyiidae). Localidade: BER. Referência: Maia et al. (2008).

Folha. Galha: dobramento ao longo da nervura mediana. Indutor: Clinodiplosis sp. (Cecidomyiidae). Localidade: BER. Referência: Maia et al. (2008).

Inga sp. $(\mathrm{n}=2)$

Folha. Galha esférica, verde. Indutor: Cecidomyiidae. Localidade: IG. Referência: Maia \& Oliveira (2010).

Folha. Galha: enrolamento e intumescência da borda foliar, verde, glabra, unilocular. Indutor: Cecidomyiidae. Localidade: PA (novo registro).

Machaerium uncinatum (Vell.) Benth. $(\mathrm{n}=2)$

Nervura foliar. Galha: dobramento ao longo da nervura central. Indutor:

Clinodiplosis sp. (Cecidomyiidae). Localidade: BER. Referência: Maia et al. (2008).

Folha. Galha globosa amarela. Indutor: Cecidomyiidae. Localidade: BER. Referência: Maia et al. (2008).

Mimosa bimucronata $(\mathrm{n}=1)$

Gema. Galha fusiforme, marrom. Indutor: Contarinia sp. (Cecidomyiidae). Localidade: GRU. Referência: Oliveira \& Maia (2005).

Ormosia arborea (Vell.) Harms $(\mathrm{n}=1)$

Folha. Galha circular. Indutor: Cecidomyiidae. Localidade: JU. Referência: Monteiro et al. (2004).

Senna bicapsularis (L.) Roxb $(\mathrm{n}=1)$

Ovário. Galha: dilatação esférica acentuada. Indutor: Asphondylia sennae Maia \& Couri, 1992 (Cecidomyiidae).
Localidade: MAR. Referências: Maia et al. (1992) e Monteiro et al. (1994).

Stylosanthes guianensis Sw. $(\mathrm{n}=1)$

Larvas predadoras na inflorescência, Lestodiplosis maricaensis Santos \& Maia, 2008 (Cecidomyiidae). Localidades: MAR, CAR e JU. Referências: Maia (2001a), Monteiro et al., (2004) e Santos \& Maia (2008)

Swartzia langsdorffii Raddi $(\mathrm{n}=1)$

Folha. Galha: lâmina foliar coalescente. Indutor: Burseramyia braziliensis Maia \& Fonseca, 2011 (Cecidomyiidae). Localidade: BER. Referência: Maia et al. (2008) (indutor identificado como Schizomyiina) e Maia \& Fonseca (2011).

Fabaceae não determinada $(\mathrm{n}=1)$

Folha. Galha linear, verde. Indutor: Cecidomyiidae. Localidade: IG. Referência: Maia \& Oliveira (2010).

$$
\text { Gesneriaceae }(n=6)
$$

Codonanthe gracilis (Mart.) Hanst. $(\mathrm{n}=4)$

Folha. Galha globosa, unilocular. Indutor: Cecidomyiidae. Localidade: BER. Referência: Maia et al. (2008).

Inflorescência. Galha: espessamento do pedúnculo. Indutor: Cecidomyiidae. Localidade: BER. Referência: Maia et al. (2008).

Nervura central. Galha espessamento fusiforme. Indutor não determinado. Localidade: BER. Referência: Maia et al. (2008).

Raiz. Galha: espessamento fusiforme. Indutor: Neolasioptera sp. (Cecidomyiidae). Localidade: BER. Referência: Maia et al. (2008).

Nematanthus fritschii Hoehne $(\mathrm{n}=2)$

Caule, pecíolo ou nervura Galha: espessamento fusiforme. Indutor: Lepidoptera. Localidade: BER. Referência: Maia et al. (2008).

Gema, Galha gongilóide, verde, crassa, pilosa. Indutor não determinado. Localidade: BER. Referência: Lima et al. (2000). Hippocrateaceae $(\mathrm{n}=1)$

Hippocratea volubilis L. $(\mathrm{n}=1)$

Pecíolo. Espessamento fusiforme. Indutor: Coleoptera. Localidade: GRU. Referência: Oliveira \& Maia (2005). Lamiaceae $(\mathrm{n}=4)$

Hyptis fasciculata Benth. subsp. fasciculata $(\mathrm{n}=1)$

Caule, pecíolo ou nervura. Galha: espessamento fusiforme. Indutor: Cecidomyiidae. Localidade: BER. Referência: Maia et al. (2008).

Hyptis lacustris A. St.-Hil. ex. Benth. $(\mathrm{n}=1)$

Caule. Galha: espessamento fusiforme. Indutor não determinado. Localidade: BER. Referência: Maia et al. (2008).

Marsypianthes chamaedrys (Vahl) Kuntze $(\mathrm{n}=1)$

Caule. Galha: espessamento fusiforme. Indutor não determinado. Localidade: BER. Referência: Maia et al. (2008).

Melissa officinalis L. $(\mathrm{n}=1)$

Folha. Galha globosa, pilosa, verde. Indutor: Clinodiplosis melissae Maia, 1993(Cecidomyiidae). Localidade: MAR. Referência: Maia (1993e).

$$
\text { Lauraceae }(n=21)
$$

Aniba viridis $\mathrm{Mez}$ 
Folha. Galha piriforme, ferrugínea, crassa, pilosa. Indutor não determinado. Localidade: BER. Referência: Lima et al. (2000).

Nectandra oppositifolia Nees $(\mathrm{n}=3)$

Folha. Galha cilíndrica, avermelhada, agregada. Indutor não determinado. Localidade: BER. Referência: Maia et al. (2008).

Folha. Galha pilosa, marrom. Indutor não determinado. Localidade: BER. Referência: Maia et al. (2008).

Folha ou caule. Galha ovóide ou globóide, avermelhada. Indutor: Neolasioptera sp. (Cecidomyiidae). Localidade: BER. Referência: Maia et al. (2008).

Ocotea aciphylla (Ness) Mez $(\mathrm{n}=3)$

Caule. Galha fusiforme, no entrenó, castanha, rígida e glabra. Indutor não determinado. Localidade: BER. Referência: Lima et al. (2000).

Pecíolo. Galha fusiforme, castanha, rígida e glabra. Indutor não determinado. Localidade: BER. Referência: Lima et al. (2000).

Caule. Galha fusiforme, no nó, castanha, rígida e glabra. Indutor não determinado. Localidade: BER. Referência: Lima et al. (2000).

Ocotea lobbii (Meisn.) Rohwer $(\mathrm{n}=2)$

Folha. Galha protuberante, aberta. Indutor: Coccidae (Hemiptera). Localidade: BER. Referência: Maia et al. (2008).

Caule. Galha: espessamento fusiforme. Indutor: não determinado. Inquilino: Trotteria sp. (Cecidomyiidae). Localidade: BER. Referência: Maia et al. (2008).

Ocolea notata (Ness) Mez. $(\mathrm{n}=4)$

Caule. Galha: espessamento fusiforme. Indutor não determinado. Localidade: JU. Referências: Monteiro et al. (1994, 2004).

Folha. Galha epidérmica. Indutor: Hemiptera. Localidades: MAR, AC, JU e GUA. Referências: Bregonci et al. (2010) e Monteiro et al. (1994, 2004).

Gema. Galha ovóide com uma projeção apical espiniforme. Indutor: Cecidomyiidi (Cecidomyiidae). Localidades: MAR, CAR e JU. Referências: Monteiro et al. (1994) e Maia (2001a).

Nervura foliar. Galha: espessamento fusiforme. Indutor não determinado. Localidade: JU Referência: Monteiro et al. (2004).

Ocotea pulchella (Nees) Mez $(\mathrm{n}=6)$

Folha. Galha: concavidade aberta. Indutor: Coccidae (Hemiptera). Localidade: BER. Referência: Maia et al. (2008).

Folha. Galha globosa, verde, pilosa. Indutor não determinado. Localidade: BER. Referência: Maia et al. (2008).

Nervura foliar. Galha: espessamento fusiforme. Indutor: Neolasioptera sp. (Cecidomyiidae). Localidade: BER. Referência: Maia et al. (2008).

Gema. Galha semelhante a um botão floral. Indutor: Clinodiplosis sp. (Cecidomyiidae). Localidade: BER. Referência: Maia et al. (2008).

Gema ou caule. Galha fusiforme. Indutor: Cecidomyiidae. Localidade: BER. Referência: Maia et al. (2008).

Caule. Galha: espessamento fusiforme. Indutor: não determinado. Inquilino: Trotteria sp. (Cecidomyiidae). Localidade: BER. Referência: Maia et al. (2008).

Caule. Galha cilíndrica, vertical. Indutor: não determinado. Localidade: BER. Referência: Maia et al. (2008).

Ocotea teleiandra (Meisn) Mez $(\mathrm{n}=1)$

Gema. Galha piriforme, castanha, rígida e glabra. Indutor não determinado. Localidade: BER. Referência: Lima et al. (2000).
Lauraceae não determinada $(\mathrm{n}=1)$

Folha. Galha piriforme, verde, crassa e glabra. Indutor não determinado. Localidade: BER. Referência: Lima et al. (2000). Loranthaceae $(\mathrm{n}=5)$

Phoradendron piperoides (H. B. \& K.) $(\mathrm{n}=1)$

Folha. Galha parenquimática, circular. Indutor: Cecidomyiidae. Localidade: MAR. Referência: Monteiro et al. (1994).

Psittacanthus dichrous (Mart.) Mart. $(\mathrm{n}=1)$

Folha. Galha parenquimática circular. Indutor: Costadiplosis maricaensis Viceconte \& Maia, 2009 (Cecidomyiidae). Localidade: MAR. Referências: Maia et al. (2001a), Monteiro et al. (1994) e Viceconte \& Maia (2009).

Struthanthus concinnus Mart. $(\mathrm{n}=2)$

Gemas laterais e apicais. Galha ovóide, com projeções apicais filiformes, bilocular. Indutor: Schizomyia sp. (Cecidomyiidae). Localidade: BER. Referência: Maia et al. (2008).

Folha ou caule. Galha suculenta, gotiforme. Indutor não determinado. Localidade: BER. Referência: Maia et al. (2008).

Sthruthanthus maricensis Rizz. (=1)

Nervura central. Galha: espessamento ovóide. Indutor: Asphondylia maricensis Maia \& Couri, 1992 (Cecidomyiidae). Localidade: MAR. Referências: Maia et al. (1992), Maia (2001a) e Monteiro et al. (1994).

$$
\text { Malpighiaceae }(\mathrm{n}=10)
$$

Byrsonima sericea DC. $(\mathrm{n}=4)$

Caule. Espessamento ovóide. Indutor: Cecidomyiidae. Localidades: IG, GRU, MAR, AC CAR e GUA. Referências: Bregonci et al. (2010), Maia (2001a), Maia \& Oliveira (2010), Monteiro et al. (1994, 2004) e Oliveira \& Maia (2005).

Fruto. Galha ovóide, verde. Indutor: Lepidoptera. Localidades: MAR e AC. Referência: Monteiro et al. (1994, 2004).

Botão floral. Galha ovóide, marrom. Indutor: Bruggmanniella byrsonimae (Maia \& Couri, 1992) (Cecidomyiidae). Localidades: MAR, CAR e JU. Referências: Maia (1999, 2001a) e Monteiro et al. (1994, 2004).

Folha. Galha parenquimática, circular. Indutor: Dasineura byrsonimae Maia, 2010 (Cecidomyiidae). Localidades: IG, GRU MAR, CAR, JU e GUA. Referências: Bregonci et al. (2010), Maia (2001a, 2010), Maia \& Oliveira (2010), Monteiro et al. (2004) e Oliveira \& Maia (2005).

Heteropteris nitida (Lam.) Kunth $(\mathrm{n}=3)$

Folha. Galha parenquimática. Indutor não determinado. Localidade: BER. Referência: Maia et al. (2008).

Folha. Galha epidérmica. Indutor não determinado. Localidade: JU. Referência: Monteiro et al. (2004).

Botão floral. Larvas livres nos botões. Clinodiplosis floricola Novo-Guedes \& Maia 2008 (Cecidomyiidae). Localidade: MAR. Referências: Maia (2001a), Novo-Guedes \& Maia (2008).

Stigmaphyllon arenicola C. E. Anderson $(\mathrm{n}=1)$

Caule. Galha: espessamento fusiforme, unilocular. Indutor não determinado. Localidade: BER. Referência: Maia et al. (2008).

Stigmaphyllon paralias A. Juss. $(\mathrm{n}=1)$

Caule. Galha: espessamento fusiforme. Indutor: Lepidoptera. Localidade: MAR. Referência: Monteiro et al. (1994).

Tetrapteris phlomoides (Spr.) Nied. $(\mathrm{n}=1)$ 
Gema. Galha: roseta de folhas. Indutor: Schizomyia maricaensis (Cecidomyiidae). Localidade: MAR. Referências: Maia (2001a), Sousa \& Maia (2007).

$$
\text { Melastomataceae }(\mathrm{n}=28)
$$

Clidemia blepharodes DC. $(\mathrm{n}=3)$

Gema. Galha globóide, vermelha, crassa e pilosa. Indutor não determinado. Localidade: BER. Referência: Lima et al. (2000).

Pecíolo. Galha fusiforme, vermelha, crassa e pilosa. Indutor não determinado. Localidade: BER. Referência: Lima et al. (2000).

Folha. Galha fusiforme, vermelha, crassa e pilosa. Indutor não determinado. Localidade: BER. Referência: Lima et al. (2000).

Clidemia neglecta D. Don $(\mathrm{n}=1)$

Folha. Galha globosa, verde e pilosa. Indutor: Cecidomyiidae. Localidades: BER e PA (novo registro). Referência: Maia et al. (2008).

Huberia ovalifolia DC. $(\mathrm{n}=2)$

Caule. Galha: espessamento fusiforme. Indutor: Lepidoptera. Localidade: BER. Referência: Maia et al. (2008).

Gemas laterais. Galha cilíndrica, unilocular. Indutor: Clinodiplosis sp. (Cecidomyiidae). Localidade: BER. Referência: Maia et al. (2008).

Leandra $\mathrm{cf}$. ionopogon (Mart.) Cogn. $(\mathrm{n}=1)$

Folha. Galha globosa, vermelha, pilosa. Indutor: Lopesia sp. (Cecidomyiidae). Localidade: BER. Referência: Maia et al. (2008).

Miconia cinnamomifolia (DC.) Naudin. $(\mathrm{n}=1)$

Caule espessamento ovóide. Indutor: Epihormomyia miconiae Maia 2001 (Cecidomyiidae). Inquilino: Resseliella sp. (Cecidomyiidae). Localidades: CAR e JU. Referências: Maia (2001a, b) e Monteiro et al. (2004).

Miconia fasciculata Gardner $(\mathrm{n}=1)$

Folha. Galha marrom fendida. Indutor: Cecidomyiidae. Localidade: BER. Referência: Maia et al. (2008).

Miconia hymenonervia (Raddi) Cogn. $(\mathrm{n}=1)$

Folha. Galha semelhante a um carapicho. Indutor não determinado. Localidade: BER. Referência: Maia et al. (2008).

Miconia pusilliflora (DC.) Naudin $(\mathrm{n}=1)$

Folha. Galha semelhante a um carapicho. Indutor não determinado. Localidade: BER. Referência: Maia et al. (2008).

Miconia rigidiuscula Cogn. $(\mathrm{n}=1)$

Nervura foliar. Galha: espessamento fusiforme, unilocular. Indutor não determinado. Localidade: BER. Referência: Maia et al. (2008).

Miconia saldanhae Cogn. $(\mathrm{n}=1)$

Folha. Galha globóide, vermelha, crassa e pilosa. Indutor não determinado. Localidade: BER. Referência: Lima et al. (2000).

Ossaea $\mathrm{sp} .(\mathrm{n}=1)$

Folha. Galha globóide, vermelha, crassa e pilosa. Indutor não determinado. Localidade: BER. Referência: Lima et al. (2000).

Pterolepis glomerata (Rottb.) Miq. $(\mathrm{n}=1)$

Caule. Galha: espessamento tênue com uma pequena abertura. Indutor não determinado. Localidade: BER. Referência: Maia et al. (2008).
Tibouchina clavata (Pers.) Wurdack $(\mathrm{n}=1)$

Caule. Galha: espessamento abrindo-se em fenda. Indutor não determinado. Localidade: BER. Referência: Maia et al. (2008).

Tibouchina mutabilis Cogn. $(\mathrm{n}=3)$

Caule. Galha fusiforme, vinácea, crassa e pilosa. Indutor não determinado. Localidade: BER. Referência: Lima et al. (2000).

Folha. Galha globóide, verde, crassa e glabra. Indutor não determinado. Localidade: BER. Referência: Lima et al. (2000).

Pecíolo. Galha fusiforme, castanha, rígida e glabra. Indutor não determinado. Localidade: BER. Referência: Lima et al. (2000).

Tibouchina pulchra Cogn. $(\mathrm{n}=3)$

Nervura central ou pecíolo. Galha: espessamento globóide, unilocular. Indutor: Curculionidae (Coleoptera). Localidade: BER. Referência: Maia et al.(2008).

Gema. Galha: espessamento globóide, plurilocular. Indutor: Lepidoptera. Localidade: BER. Referência: Maia et al. (2008).

Folha. Galha globosa, verde, pilosa. Indutor: Lopesia sp. (Cecidomyiidae). Localidade: BER. Referência: Maia et al. (2008).

Tibouchina trichopoda (DC.) Baill. $(\mathrm{n}=5)$

Folha ou caule. Galha globóide, pilosa. Indutor: Lasiopteridi (Cecidomyiidae). Localidade: BER. Referência: Maia et al. (2008).

Pecíolo. Galha: espessamento fusiforme. Indutor não determinado. Localidade: BER. Referência: Maia et al. (2008).

Nervura foliar. Galha: espessamento fusiforme. Indutor: Cecidomyiidae. Localidade: BER. Referência: Maia et al. (2008).

Caule. Galha: espessamento fusiforme. Indutor: Cecidomyiidae. Localidade: BER. Referência: Maia et al. (2008).

Gema ou caule. Galha ovóide. Indutor: Lepidoptera. Localidade: BER. Referência: Maia et al. (2008).

Melastomataceae não determinada $(\mathrm{n}=1)$

Caule. Galha: espessamento fusiforme, marrom, unilocular. Indutor não determinado. Localidade: IG. Referência: Maia \& Oliveira (2010).

$$
\text { Meliaceae }(\mathrm{n}=3)
$$

Guarea macrophylla Vahl subsp. Tuberculata (Vell.) T. D. Penn. $(\mathrm{n}=3)$

Folha. Galha globosa, vermelha. Indutor: Guareamyia purpura Maia, 2007 (Cecidomyiidae). Localidade: BER. Referências: Maia (2007) e Maia et al. (2008).

Folha. Galha globosa, amarela. Indutor: Sphaeromyia flava Maia, 2007 (Cecidomyiidae). Localidade: BER. Referências: Maia (2007), Maia et al. (2008).

Nervura foliar. Galha: espessamento fusiforme. Indutor: Neolasioptera sp. (Cecidomyiidae). Localidade: BER. Referência: Maia et al. (2008).

$$
\text { Moraceae }(\mathrm{n}=2)
$$

Ficus enormis (Mart. Ex. Miq.) Miq. $(\mathrm{n}=1)$

Folha. Galha parenquimática, circular, amarelada, unilocular. Indutor: Cecidomyiidae. Localidade: BER. Referência: Maia et al. (2008).

Ficus guaranitica Chodat ex Chodat \& Vischer $(\mathrm{n}=1)$

Folha. Galha: enrolamento da borda. Indutor: Clinodiplosis sp. (Cecidomyiidae). Localidade: BER. Referência: Maia et al. (2008).

$$
\text { Myrsinaceae }(\mathrm{n}=5)
$$


Rapanea ferruginea (Ruiz \& Pav.) Mez $(\mathrm{n}=2)$

Caule. Galha: espessamento fusiforme, unilocular. Indutor: Lepidoptera. Localidade: BER. Referência: Maia et al. (2008).

Folha. Galha parenquimática, amarela, unilocular Indutor: Cecidomyiidae. Localidade: BER. Referência: Maia et al. (2008).

Rapanea parvifolia (A. DC.) Mez. $(\mathrm{n}=2)$

Folha. Galha parenquimática, circular. Indutor: Cecidomyiidae. Localidades: MAR, CAR e JU. Referências: Maia (2001a), Monteiro et al. (1994, 2004).

Caule. Galha: espessamento fusiforme. Indutor: Lepidoptera. Localidades: MAR e AC. Referências: Maia (2006), Monteiro et al. (1994, 2004).

Rapanea sp. $(\mathrm{n}=1)$

Caule. Galha: espessamento fusiforme, marrom. Indutor: Lepidoptera. Localidade: IG. Referência: Maia \& Oliveira (2010). Myrtaceae $(n=97)$

Blepharocalyx salicifolius (Kunth) O. Berg ( $\mathrm{n}=1)$

Nervura foliar. Galha: espessamento lenhoso. Indutor não determinado. Localidade: BER. Referência: Maia et al. (2008).

Calyptranthes sp. $(\mathrm{n}=4)$

Folha. Galha parenquimática, unilocular. Indutor não determinado. Localidade: BER. Referência: Maia et al. (2008).

Folha. Galha: dobramento ao longo da nervura central. Indutor não determinado. Localidade: BER. Referência: Maia et al. (2008)

Caule. Galha: espessamento fusiforme Indutor não determinado. Localidade: JU. Referência: Monteiro et al. (2004).

Nervura foliar. Galha globóide, unilocular. Indutor: Clinodiplosis sp. (Cecidomyiidae). Localidade: BER. Referência: Maia et al. (2008).

Eugenia adstringens Cambess. ( = E.rotundifolia Casar e E. umbelliflora O. Berg) $(\mathrm{n}=7)$

Folha. Galha: enrolamento da borda. Indutor: Jorgenseniella eugeniae Maia, 2005 (Cecidomyiidae). Localidades: GRU, MAR, AC, CAR e JU. Referência: Maia (2001a), Maia et al. 2005, Monteiro et al. (1994, 2004) e Oliveira \& Maia (2005).

Gema. Galha cilíndrica, marrom. Indutor: Stephomyia rotundifoliorum Maia, 1993 (Cecidomyiidae). Localidades: MAR, AC, CAR e JU. Referências: Maia (1993c, 2001a) e Monteiro et al. (1994).

Folha. Galha circular, amarela. Indutor: Dasineura globosa Maia, 1993 (Cecidomyiidae). Localidades: GRU, MAR, CAR e JU. Referências: Maia (1993d, 2001a), Monteiro et al. (2004) e Oliveira \& Maia (2005).

Folha. Galha triangular. Indutor: Cecidomyiinae (Cecidomyiidae). Localidades: CAR e JU. Referências: Maia (2001a) e Monteiro et al. (2004).

Folha. Galha piriforme. Indutor: Cecidomyiinae (Cecidomyiidae). Localidades: CAR e JU. Referências: Maia (2001a) e Monteiro et al. (2004).

Folha. Galha claviforme. Indutor: Stephomyia clavata (Tavares 1920) (Cecidomyiidae). Localidades: CAR e JU. Referências: Maia (2001a) e Monteiro et al. (2004).

Caule. Indutor não determinado. Localidade: JU. Referência: Monteiro et al. (2004).

Folha. Galha parenquimática, circular. Indutor: Lasiopteridi. Localidade: BER. Maia et al. (2008).

Eugenia copacabanensis Kiaersk. $(\mathrm{n}=7)$
Folha. Galha espiralada. Indutor: Stephomyia espiralis Maia 1993 (Cecidomyiidae). Localidade: MAR. Referências: Maia (1993c, 2001a) e Monteiro et al. (2004).

Folha. Galha cônica. Indutor: Stephomyia tetralobae Maia 1993 (Cecidomyiidae). Localidade: MAR. Referências: Maia (1993c, 2001a) e Monteiro et al. (2004).

Gema. Galha cônica, pedunculada. Indutor: Dasineura copacabanensis Maia, 1993 (Cecidomyiidae). Localidade: AR. Referência: Maia (1993a) e Monteiro et al. (2004).

Folha. Galha: enrolamento da folha jovem. Indutor: Dasineura sp. (Cecidomyiidae). Localidade: MAR. Referência: Maia et al. (2002).

Folha. Indutor: Cecidomyiidae. Localidade: MAR. Referência: Monteiro et al. (2004).

Caule. Indutor: Cecidomyiidae. Localidade: MAR e AC Referência: Monteiro et al. (1994).

Caule. Indutor: Hymenoptera. Localidade: AC. Referência: Monteiro et al. (1994).

Eugenia monosperma Vell. $(\mathrm{n}=2)$

Folha. Galha amarela, globosa, unilocular. Indutor não determinado. Localidade: BER. Referência: Maia et al. (2008).

Folha. Galha parenquimática, circular, unilocular. Indutor não determinado. Localidade: BER. Referência: Maia et al. (2008).

Eugenia multiflora (Lam.) DC. $(\mathrm{n}=7)$

Folha. Galha: enrolamento da folha inteira ou borda. Indutor: Thysanoptera. Localidade: BER. Referência: Maia et al. (2008).

Gema. Galha cilíndrica, marrom. Indutor: Stephomyia sp.

(Cecidomyiidae). Localidade: CAR. Referência: Maia (2001a).

Folha. Galha circular, verde. Indutor: Lasiopteridi

(Cecidomyiidae). Localidade: CAR. Referência: Maia (2001a).

Folha. Enrolamento da borda. Indutor: Cecidomyiinae.

Localidade: CAR. Referência: Maia (2001a).

Folha. Galha piriforme, amarela. Indutor: Cecidomyiinae. Localidade: CAR. Referência: Maia (2001a).

Folha. Galha claviforme, verde ou vermelha. Indutor:

Stephomyia cfr. clavata (Tavares, 1920) (Cecidomyiidae). Localidade: CAR. Referência: Maia (2001a).

Folha. Galha triangular, amarela. Indutor: Cecidomyiinae. Localidade: CAR. Referência: Maia (2001a).

Eugenia ovalifolia Cambess $(\mathrm{n}=5)$

Folha. Indutor: Cecidomyiidae. Localidade: AC. Referência: Monteiro et al. (1994).

Caule. Indutor: Hymenoptera. Localidade: MAR. Referência: Monteiro et al. (1994).

Fruto. Indutor: Cecidomyiidae. Localidade: MAR. Referência: Monteiro et al. (1994).

Caule. Indutor não determinado. Localidade: JU. Referência: Monteiro et al. (2004).

Caule. Galha: espessamento fusiforme, marrom. Indutor não determinado. Localidade: GRU. Referência: Oliveira \& Maia (2005).

Eugenia riedeliana $\mathrm{O}$. Berg $(\mathrm{n}=1)$

Folha. Galha cônica, castanha, crassa e glabra. Indutor não determinado. Localidade: BER. Referência: Lima et al. (2000).

Eugenia speciosa Cambess. $(\mathrm{n}=2)$

Folha. Galha gotiforme, amarela, unilocular. Indutor: Schizomyiina (Cecidomyiidae). Localidade: BER. Referência: Maia et al. (2008). 
Folha. Galha claviforme. Indutor: Schizomyiina (Cecidomyiidae). Localidade: BER. Referência: Maia et al. (2008).

Eugenia stigmatosa DC. $(\mathrm{n}=1)$

Folha. Galha globóide, ferrugínea, crassa e glabra. Indutor não determinado. Localidade: BER. Referência: Lima et al. (2000).

Eugenia sulcata Spring $(\mathrm{n}=2)$

Gema. Galha cilíndrica, vermelha e unilocular. Indutor não determinado. Localidade: BER. Referência: Maia et al. (2008)

Gema. Galha verde. Indutor não determinado. Localidade: BER. Referência: Maia et al. (2008).

Eugenia uniflora L. $(\mathrm{n}=6)$

Folha. Galha esponjosa. Indutor: Eugeniamyia dispar Maia, Mendonça \& Romanovski, 1996 (Cecidomyiidae). Localidade: BER. Referências: Maia et al. 1996 e Maia et al. (2008).

Folha. Galha cônica. Indutor: Clinodiplosis profusa Maia 2001 (Cecidomyiidae). Localidades: GRU, MAR, AC, CF (novo registro), CAR e JU. Referências: Maia (2001a, b), Monteiro et al. (1994, 2004) e Oliveira \& Maia (2005).

Folha. Galha parenquimática, circular. Indutor: Neolasioptera eugeniae Maia 1993 (Cecidomyiidae) Localidades: PA (novo registo), IG, GRU, MAR, CF (novo registro) e AC. Referências: Maia (1993a, 2001a), Maia \& Oliveira (2010), Monteiro et al. (1994) e Oliveira \& Maia (2005).

Fruto. Galha triangular, vermelha. Indutor: Cecidomyiidae. Localidade: MAR. Referência: Monteiro et al. (1994).

Botão floral. Galha triangular, vermelha. Indutor: Cecidomyiidae. Localidade: GRU. Referência: Oliveira \& Maia (2005).

Caule. Galha: espessamento fusiforme, marrom. Indutor não determinado. Localidade: IG. Referência: Maia \& Oliveira (2010).

Eugenia sp. $(\mathrm{n}=5)$

Folha. Galha: enrolamento da borda. Indutor: Cecidomyiidae.

Localidade: GRU. Referência: Oliveira \& Maia (2005).

Folha. Galha discóide, amarela. Indutor: Cecidomyiidae.

Localidade: GRU. Referência: Oliveira \& Maia (2005).

Folha. Galha cilíndrica, verde. Indutor: Cecidomyiidae.

Localidade: IG. Referência: Maia \& Oliveira (2010).

Folha. Galha circular, verde. Indutor: Cecidomyiidae.

Localidade: IG. Referência: Maia \& Oliveira (2010).

Caule. Galha: espessamento fusiforme. Indutor não determinado. Localidades: GRU e IG. Referências: Maia \& Oliveira (2010) e Oliveira \& Maia (2005).

Gomidesia fenzliana $\mathrm{O}$. Berg $(\mathrm{n}=1)$

Caule. Galha: espessamento fusiforme, unilocular. Indutor:

Pacholenus pelliceus Boheman, 1836(Coleoptera: Curculionidae).

Localidades: BER e MAR. Referências: Monteiro et al. (1994).

Gomidesia schaueriana O. Berg $(\mathrm{n}=3)$

Gemas laterais e apicais. Galha ovóide, purilocular. Indutor não determinado. Localidade: BER. Referência: Maia et al. (2008).

Folha. Galha parenquimática. Indutor: Bruggmanniella cfr. (Cecidomyiidae). Localidade: BER. Referência: Maia et al. (2008).

Caule. Galha: espessamento fusiforme, unilocular. Indutor: Coleoptera. Localidade: MAR. Referência: Monteiro et al. (1994).

Myrcia fallax (Rich.) DC. $(\mathrm{n}=7)$
Caule. Galha: espessamento globóide. Indutor: Oligotrophini (Cecidomyiidae). Localidade: BER. Referência: Maia et al. (2008).

Nervura foliar. Galha: espessamento globóide. Indutor: Oligotrophini (Cecidomyiidae). Localidade: BER. Referência: Maia et al. (2008).

Gema. Indutor: Lasiopteridi (Cecidomyiidae). Localidade: BER. Referência: Maia et al. (2008).

Caule. Galha: espessamento fusiforme, plurilocular. Indutor: Cecidomyiidae. Localidade: BER. Referência: Maia et al. (2008)

Folha. Galha: intumescimento e enrolamento da folha jovem. Indutor não determinado. Localidade: BER. Referência: Maia et al. (2008).

Caule e nervura. Galha: espessamento fusiforme. Indutor: Lasiopteridi (Cecidomyiidae). Inquilino: Trotteria sp. (Cecidomyiidae). Localidade: BER. Referência: Maia et al. (2008).

Gema. Galha semelhante a um botão, gotiforme. Indutor não determinado. Predador: Lestodiplosis sp.(Cecidomyiidae). Localidade: BER. Referência: Maia et al. (2008).

Myrcia lundiana Kiaersk $(\mathrm{n}=6)$

Folha. Galha globular. Indutor: Dasineura sp. (Cecidomyiidae). Localidade: MAR. Referência: Maia (2001a) e Monteiro et al. (2004).

Folha. Indutor não determinado. Localidade: MAR. Referência: Monteiro et al. (1994).

Gema. Galha ovóide, sulcada. Indutor: Myrciamyia maricaensis Maia 1995 (Cecidomyiidae). Localidades: MAR, AC, CAR e JU. Referências: Maia (1995, 2001a) e Monteiro et al. (2004).

Pedúnculo floral. Espessamento fusiforme. Indutor: Cecidomyiidae. Localidade: MAR. Referências: Maia (2001) e Monteiro et al. (2004).

Folha. Galha epidérmica. Indutor não determinado. Localidade: JU. Referência: Monteiro et al. (2004).

Nervura foliar. Indutor não determinado. Localidade: JU. Referência: Monteiro et al. (2004).

Myrcia macrocarpa DC. $(\mathrm{n}=1)$

Gema. Galha globóide, verde, crassa, glabra. Indutor não determinado. Localidade: BER. Referência: Lima et al. (2000).

Myrcia multiflora (Lam.) DC. $(\mathrm{n}=1)$

Folha. Galha: enrolamento da folha inteira ou borda foliar. Indutor: Thysanoptera. Localidade: BER. Referência: Maia et al. (2008).

Myrcia ovata Camb. $(\mathrm{n}=4)$

Folha. Galha globular. Indutor: Dasineura sp. (Cecidomyiidae). Localidade: MAR. Referências: Maia (2001a), Maia et al. (2002) e Monteiro et al. (2004).

Folha. Indutor não determinado. Localidade: MAR. Referência: Monteiro et al. (1994).

Gema. Galha ovóide, sulcado. Indutor: Myrciamyia maricaensis Maia 1995 (Cecidomyiidae). Localidades: MAR, AC, CAR e JU. Referências: Maia (1995, 2001a) e Monteiro et al. (2004).

Pedúnculo floral. Galha: espessamento fusiforme. Indutor: Cecidomyiidae. Localidade: MAR. Referências: Maia (2001a) e Monteiro et al. (2004).

Myrcia palustris DC. $(\mathrm{n}=2)$

Folha. Galha parenquimática, circular, unilocular. Indutor não determinado. Localidade: BER. Referência: Maia et al. (2008). 
Gema. Galha ovóide, multilocular. Indutor não determinado. Localidade: BER. Referência: Maia et al. (2008).

Myrciaria floribunda (West ex Willdenow) Berg. $(\mathrm{n}=7)$

Folha. Galha: enrolamento da borda. Indutor: Dasineura myrciariae Maia, 1993 (Cecidomyiidae). Localidades: MAR, CAR, JU e GUA. Referências: Bregonci et al. (2010), Maia (1993d) e Monteiro et al. (1994, 2004).

Folha. Galha: enrolamento da folha inteira. Indutor: Thysanoptera. Localidade: MAR. Referência: Monteiro et al. (1994).

Gema. Galha bivalva, amarela. Indutor: Myrciariamyia bivalva Maia, 1994 (Cecidomyiidae). Localidades: MAR, AC, CAR e JU. Referências: Maia (1994, 2001a) e Monteiro et al. (1994, 2004).

Folha. Galha em forma de estrela. Indutor: Cecidomyiidae. Localidades: MAR e CAR. Referência: Maia (2001a).

Folha. Galha epidérmica. Indutor não determinado. Localidade: JU. Referência: Monteiro et al. (2004).

Folha. Galha globosa, glabra. Indutor: Cecidomyiidae. Localidade: GUA. Referência: Bregonci et al. (2010).

Caule. Galha globosa, verde, glabra. Indutor não determinado. Localidade: GUA. Referência: Bregonci et al. (2010).

Myrciaria jaboticaba (Vell.) Berg $(\mathrm{n}=2)$

Folha. Galha: enrolamento marginal, verde. Indutor: Cecidomyiidae. Localidade: IG. Referência: Maia \& Oliveira (2010).

Gema. Galha cilíndrica, verde. Indutor: Cecidomyiidae. Localidade: IG. Referência: Maia \& Oliveira (2010).

Neomitranthes obscura (DC.) N. J. E. Silveira $(n=6)$

Folha. Galha triangular. Indutor: Cecidomyiinae. Localidades: MAR, AC, CAR e JU. Referências: Maia \& Couri (1997) e Maia (2001a), Monteiro et al. (2004).

Folha. Galha: enrolamento da folha inteira. Indutor: Thysanoptera. Localidade: MAR e AC. Referência: Maia (2006) e Monteiro et al. (1994).

Folha. Galha elíptica Indutor: Stephomyia mina Maia, 1993 (Cecidomyiidae). Localidades: MAR e CAR. Referências: Maia (1993c, 2001a) e Monteiro et al. (2004).

Folha. Galha: enrolamento da borda. Indutor: Clinodiplosis sp. (Cecidomyiidae). Localidades: MAR, CAR, JU e GUA. Referências: Bregonci et al. (2010), Maia (2001a) e Monteiro et al. (2004).

Gema. Galha semelhante a um ananás. Indutor: Neomitranthella robusta Maia, 1995 (Cecidomyiidae). Localidades: MAR, CAR e JU. Referências: Maia (1995, 2001a) e Monteiro et al. (2004).

Caule. Galha: espessamento fusiforme. Indutor não determinado. Localidade: JU. Referência: Monteiro et al. (2004).

Psidium cattleyanum Sabine $(\mathrm{n}=7)$

Folha. Galha tubular, unilocular. Indutor: Lasiopteridi (Cecidomyiidae). Localidade: BER. Referência: Maia et al. (2008).

Gema. Galha: roseta de folhas. Indutor: Dasineura gigantea Angelo \& Maia, 1999 (Cecidomyiidae). Localidade: BER. Referências: Angelo \& Maia (1999) e Maia et al. (2008).

Folha. Galha cônica com pequenas projeções apicais. Indutor: Cecidomyiidae. Localidade: BER. Referência: Maia et al. (2008).

Folha. Galha globosa, unilocular. Indutor não determinado. Localidade: BER, Referência: Maia et al. (2008).

Folha. Galha parenquimática: Indutor: Cecidomyiidae: Localidade: BER. Referência: Maia et al. (2008).
Folha. Galha cônica, com duas projeções cônicas (uma na superfície abaxial e outra na adaxial da folha), verde, glabra. Indutor: Hemiptera. Localidade: IG. Referência: Maia \& Oliveira (2010).

Folha ou gema. Galha esferóide, amarela, glabra. Indutor: Cecidomyiidae. Localidade: IG. Referência: Maia \& Oliveira (2010).

Myrtaceae não determinada $(\mathrm{n}=1)$

Caule. Galha globosa, marrom, glabra. Indutor não determinado. Localidade: GUA. Referência: Bregonci et al. (2010).

Nyctaginaceae $(\mathrm{n}=15)$

Guapira nitida (Mart. Ex Schmidt) Lundell $(\mathrm{n}=2)$

Folha. Galha parenquimática, verde, unilocular. Indutor: Bruggmannia sp. (Cecidomyiidae). Localidade: BER. Referência: Maia et al. (2008).

Folha. Galha globóide, castanha, crassa e glabra. Indutor não determinado. Localidade: BER. Referência: Lima et al. (2000).

Guapira opposita (Vell.) Reitz $(\mathrm{n}=10)$

Caule. Galha: espessamento fusiforme discreto, unilocular. Indutor: Bruggmannia sp. (Cecidomyiidae). Localidade: BER. Referência: Maia et al. (2008).

Gema. Galha esférica, pilosa. Indutor: Bruggmannia monteiroi Maia \& Couri, 1993 (Cecidomyiidae). Localidades: MAR, AC e JU Referências: Maia \& Couri (1993) e Monteiro et al. (1994).

Folha. Galha globosa, vermelha, pilosa. Indutor: Bruggmannia robusta Maia \& Couri 1993 (Cecidomyiidae). Localidades: BER, IG, MAR, AC, CAR e JU. Referências: Maia \& Couri (1993), Maia (2001a), Maia et al. (2008), Maia \& Oliveira (2010) e Monteiro et al. (2004).

Folha. Galha parenquimática, circular. Indutor: Bruggmannia elongata Maia \& Couri 1993 (Cecidomyiidae). Localidades: BER, IG, MAR, AC, CAR e JU. Referências: Maia \& Couri (1993), Maia (2001a), Maia et al. (2008), Maia \& Oliveira (2010) e Monteiro et al. (1994).

Folha. Galha triangular. Indutor: Bruggmannia acaudata Maia, 2004 (Cecidomyiidae) Localidades: IG, MAR, CAR e JU. Referências: Maia (2001a, 2004), Maia \& Oliveira (2010) e Monteiro et al. (2004).

Gema. Galha: roseta de folhas. Indutor: Pisphondylia braziliensis Couri \& Maia, 1992 (Cecidomyiidae). Localidades: BER, MAR e JU. Referências: Couri \& Maia (1992), Maia (2001a), Maia et al. (2008) e Monteiro et al. (2004).

Caule. Galha: espessamento ovóide. Indutor: Proasphondylia guapirae Maia, 1993 Localidades: BER, IG, MAR, CAR e JU. Referências: Maia (1993b, 2001a), Maia et al. (2008), Maia \& Oliveira (2010) e Monteiro et al. (2004).

Caule. Espessamento fusiforme. Indutor: Proasphondylia formosa Maia 1993 (Cecidomyiidae). Localidades: MAR, CAR e JU. Referências: Maia (1993) e Monteiro et al. (2004).

Caule. Espessamento fusiforme. Indutor: Hymenoptera. Localidade: MAR. Referência: Monteiro et al. (1994).

Folha. Galha globosa, verde. Indutor: Cecidomyiidae Localidades: BER e GUA. Referências: Bregonci et al. (2010) e Maia et al. (2008).

Guapira pernambucensis $(\mathrm{n}=2)$

Folha. Galha circular, verde. Indutor: Cecidomyiidae. Localidade: GRU. Referência: Oliveira \& Maia (2005).

Folha. Galha globosa, rosa, pilosa. Indutor: Bruggmannia sp. (Cecidomyiidae). Localidade: GUA. Referência: Bregonci et al. (2010). 
Guapira sp. $(\mathrm{n}=1)$

Folha. Galha cônica, verde ou marrom, glabra. Indutor não determinado. Localidade: GUA. Referência: Bregonci et al.. (2010).

$$
\text { Ochnaceae }(\mathrm{n}=3)
$$

Ouratea cuspidata (St. Hil.) Engl. $(\mathrm{n}=3)$

Folha. Galha cilíndrica, marrom, com projeção delgada e tubular apicalmente. Indutor: Contarinia sp. (Cecidomyiidae). Localidades: IG, GRU, MAR, JU e GUA. Referências: Bregonci et al. (2010), Maia (2001a), Maia \& Oliveira (2010), Monteiro et al. (2004) e Oliveira \& Maia (2005).

Folha. Galha parenquimática, circular, amarela, glabra. Indutor: Cecidomyiidae. Localidade: IG. Referência: Maia \& Oliveira (2010).

Folha. Galha: enrolamento da borda, verde, glabro. Indutor não determinado. Localidade: GUA. Referência: Bregonci et al. (2010).

Olacaceae $(\mathrm{n}=1)$

Ximenia americana L. var. americana $(\mathrm{n}=1)$

Caule. Galha: espessamento ovóide, marrom. Indutor: Asphondylia communis Maia \& Couri, 1993 (Cecidomyiidae). Localidade: MAR. Referências: Maia (2001a), Maia \& Couri (1993) e Monteiro et al. (1994).

$$
\text { Onagraceae }(n=1)
$$

Ludwigia octovalvis (Jacq.) P. H. Raven ( $\mathrm{n}=1)$

Gema. Galha cilíndrica, verde, pilosa. Indutor: Clinodiplosis sp. (Cecidomyiidae). Localidade: BER. Referência: Maia et al. (2008).

$$
\text { Orchidaceae }(\mathrm{n}=1)
$$

Epidendrum denticulatum $(\mathrm{n}=1)$

Folha. Galha circular, marrom, glabra. Indutor não determinado. Localidade: GUA. Referência: Bregonci et al. (2010). Passifloraceae $(\mathrm{n}=1)$

Passiflora mucronata Lam. $(\mathrm{n}=1)$

Folha. Galha: enrolamento da folha jovem. Indutor: Clinodiplosis sp. (Cecidomyiidae). Localidades: MAR, CAR e JU. Referências: Maia (2001a), Monteiro et al. (2004).

$$
\text { Phytolaccaceae }(\mathrm{n}=1)
$$

Phitolacca cfr. esculenta Van Houtte $(\mathrm{n}=1)$

Gema. Roseta de folhas. Indutor: Asphondyliina (Cecidomyiidae). Localidade: MAR. Referência: Maia et al. (2002b).

$$
\text { Picramniaceae }(\mathrm{n}=1)
$$

Picramnia gardneri Planch. $(\mathrm{n}=1)$

Folha. Galha globosa. Indutor não determinado. Localidade: BER. Referência: Maia et al. (2008).

$$
\text { Piperaceae }(n=6)
$$

Piper glabella (Sw.) A. Dietr. $(\mathrm{n}=3)$

Caule. Galha:espessamento unilocular. Indutor não determinado. Localidade: BER. Referência: Maia et al. (2008).

Folha. Galha parenquimática, unilocular. Indutor: Cecidomyiidae. Localidade: BER. Referência: Maia et al. (2008).

Inflorescência. Galha fusiforme, verde, crassa e glabra. Indutor não determinado. Localidade: BER. Referência: Lima et al. (2000).

Piper amalago $(\mathrm{n}=1)$
Caule. Galha: espessamento fusiforme verde. Indutor: Cecidomyiidae. Localidade: GRU. Referência: Oliveira \& Maia (2005).

Piper arboreum Aubl. $(\mathrm{n}=1)$

Folha. Galha ovóide, unilocular. Indutor não determinado. Localidade: BER. Referência: Maia et al. (2008).

Piper divaricatum Meyer $(\mathrm{n}=1)$

Larvas de Cecidomyiidae livres na inflorescência. Localidade: CAR. Referência: Maia (2001a).

$$
\text { Poaceae }(n=1)
$$

Paspalum maritimum Trin.

Folha. Galha circular. Indutor não determinado. Localidade: BER. Referência: Maia et al. (2008).

$$
\text { Polygonaceae }(n=5)
$$

Coccoloba mosenii Lindl. $(\mathrm{n}=1)$

Caule. Galha: espessamento fusiforme. Indutor: Cecidomyiidae. Localidade: BER. Referência: Maia et al. (2008).

Coccoloba cf. warmingii Meisn. $(\mathrm{n}=2)$

Folha. Galha parenquimática. Indutor: Cecidomyiidae. Localidade: BER. Referência: Maia et al. (2008).

Folha. Galha globóide. Indutor não determinado. Localidade:

BER. Referência: Maia et al. (2008).

Coccolobasp. $(\mathrm{n}=1)$

Folha. Galha epidérmica. Indutor não determinado. Localidade:

JU. Referência: Monteiro et al. (2004).

Polygonum punctatum Heil. $(\mathrm{n}=1)$

Folha. Galha fusiforme, verde, crassa e glabra. Indutor não determinado. Localidade: BER. Referência: Lima et al. (2000). Polypodiaceae $(\mathrm{n}=1)$

Microgramma vacciniifolia (Langsd. \& Fisch.) Copel. $(\mathrm{n}=1)$

Gema. Galha ovóide, verde, com pilosidade branca. Indutor: Primadiplosis microgrammae Maia, 2011 (Cecidomyiidae). Localidade: MAR. Referência: Maia \& Santos (2011). Rubiaceae $(\mathrm{n}=13)$

Alibertia aff. Myrciifolia K. Schum. $(\mathrm{n}=1)$

Caule. Galha: espessamento fusiforme. Indutor não determinado. Localidade: BER. Referência: Maia et al. (2008).

Borreria cf. ocymifolia (Willd. Ex Roem. \& Schult.) Bacigalupo \& E. L. Cabral $(\mathrm{n}=1)$

Caule. Galha: espessamento fusiforme. Indutor: Neolasioptera sp. (Cecidomyiidae). Localidade: BER. Referência: Maia et al. (2008).

Borreria verticillata (L.) Meyer $(\mathrm{n}=1)$

Inflorescência. Galha triangular. Indutor: Asphondylia borreriae Rübsaamen, 1905 (Cecidomyiidae). Localidades: MAR, AC, CAR e JU. Referências: Maia (2001a) e Monteiro et al. (1994, 2004).

Diodia gymnocephala (DC.) K. Schum ( $\mathrm{n}=1)$

Caule. Galha: espessamento fusiforme. Indutor: Clinodiplosis diodiae Maia, 2001 (Cecidomyiidae). Localidades: CAR e JU. Referências: Maia (2001a) e Monteiro et al. (2004).

Diodia radula $(\mathrm{n}=1)$ 
Inflorescência. Galha: espessamento fusiforme do pedúnculo, verde. Indutor: Cecidomyiidae. Localidade: GRU. Referência: Oliveira \& Maia (2005).

Emmeorhiza umbellata (Spreng.) K. Schum. $(\mathrm{n}=1)$

Caule ou gema. Galha: espessamento ovóide, plurilocular. Indutor não determinado. Localidade: BER. Referência: Maia et al. (2008).

Psychotria carthagenensis Jacq. $(\mathrm{n}=1)$

Gema. Galha verde-rósea, globóide, suculenta, multilocular. Indutor: Oligotrophini (Cecidomyiidae). Localidade: BER. Referência: Maia et al. (2008).

Psychotria hoffmannseggiana (Willd. \& Hoffg. Ex Roem. \& Schult.) Müll. Arg. $(\mathrm{n}=1)$

Folha. Galha globóide, unilocular. Indutor: Neolasioptera sp. (Cecidomyiidae). Localidade: BER. Referência: Maia et al. (2008)

Psychotria leiocarpa Cham. \& Schltdl. $(\mathrm{n}=2)$

Folha. Galha globóide, unilocular, com sulcos longitudinais. Indutor: Dasineura sp. (Cecidomyiidae). Localidade: BER. Referência: Maia et al. (2008).

Folha. Galha cônica, verde, crassa e glabra. Indutor não determinado. Localidade: BER. Referência: Lima et al. (2000).

Psychotria mapourioides DC. $(\mathrm{n}=1)$

Gema. Galha gongilóide, rósea, crassa e glabra. Indutor não determinado. Localidade: BER. Referência: Lima et al.. (2000).

Salzmania nitida $(\mathrm{n}=1)$

Fruto. Galha globosa, rosa, glabra. Indutor não determinado. Localidade: GUA. Referência: Bregonci et al. (2010).

Rubiaceae não determinada $(\mathrm{n}=1)$

Caule. Galha gongilóide, verde, crassa e glabra. Indutor não determinado. Localidade: BER. Referência: Lima et al. (2000). Sapindaceae $(\mathrm{n}=20)$

Matayba guianensis Aubl. $(\mathrm{n}=2)$

Folha. Galha globosa, amarela. Indutor não determinado. Localidade: BER. Referência: Maia et al. (2008).

Folha. Galha cônica, com sulcos longitudinais, unilocular. Indutor: Paulliniamyia ampla Maia, 2001 (Cecidomyidae) Localidade: BER. Referência: Maia et al. (2008).

Paullinia micrantha Cambess. $(\mathrm{n}=1)$

Caule. Galha: espessamento discreto, multilocular. Indutor não determinado. Localidade: BER. Referência: Maia et al. (2008).

Paullinia weinmanniaefolia Mart. $(\mathrm{n}=6)$

Folha. Galha cônica. Indutor: Paulliniamyia ampla Maia 2001 (Cecidomyiidae). Localidades: MAR, AC, CAR e JU. Referências: Maia (2001a, b) e Monteiro et al. (1994, 2004).

Gavinha. Galha: espessamento fusiforme. Indutor: Cecidomyiidae. Localidade: CAR. Referência: Maia (2001a).

Folha. Galha: enrolamento da folha jovem. Indutor: Clinodiplosis costai Maia 2005 (Cecidomyiidae). Localidades: MAR, CAR e JU. Referências: Maia (2001a, 2005) e Monteiro et al. (2004).

Folha. Galha claviforme. Indutor não determinado. Localidade: JU. Referência: Monteiro et al. (2004).

Folha. Galha epidérmica. Indutor não determinado. Localidade: JU. Referência: Monteiro et al. (2004).
Caule. Indutor não determinado. Localidade: JU. Referência: Monteiro et al. (2004).

Paullinia sp. $(\mathrm{n}=6)$

Caule. Galha: espessamento fusiforme. Indutor: Lepidoptera.

Localidade: BER. Referência: Maia et al. (2008).

Nervura, pecíolo, ou gavinha. Galha: espessamento unilocular. Indutor: Neolasioptera sp. (Cecidomyiidae). Localidade: BER. Referência: Maia et al. (2008).

Folha. Galha: enrolamento da folha jovem. Indutor: Clinodiplosis costai Maia, 2005 (Cecidomyiidae). Localidade: BER. Referência: Maia et al. (2008).

Folha. Galha parenquimática, linear. Indutor: Neolasioptera sp. Localidade: BER. Referência: Maia et al. (2008).

Folha. Galha globosa. Indutor: Cecidomyiidae. Localidade: BER. Referência: Maia et al. (2008).

Folha. Galha gotiforme. Indutor: Cecidomyiidae. Localidade: BER. Referência: Maia et al. (2008).

Serjania communis Cambess. $(\mathrm{n}=1)$

Gema. Galha esférica, agregada. Indutor: Clinodiplosis sp. (Cecidomyiidae) Localidade: BER. Referência: Maia et al. (2008).

Urvillea stipitata Radlk. $(\mathrm{n}=3)$

Nervura foliar. Galha: espessamento fusiforme, verde. Indutor: Cecidomyiidae. Localidade: GRU. Referência: Oliveira \& Maia (2005).

Folha. Galha cônica, verde. Indutor: Cecidomyiidae. Localidade: GRU. Referência: Oliveira \& Maia (2005).

Gema. Galha ovóide, verde. Indutor: Cecidomyiidae. Localidade: GRU. Referência: Oliveira \& Maia (2005).

Sapindaceae não determinada $(\mathrm{n}=1)$

Folha. Galha piriforme, verde, crassa e glabra. Indutor não determinado. Localidade: BER. Referência: Lima et al. (2000). Sapotaceae $(\mathrm{n}=12)$

Bumelia obtusifolia $(\mathrm{n}=1)$

Folha. Indutor: Cecidomyiidae. Localidade: MAR. Referência: Monteiro et al. (1994).

Manilkara subsericea (Mart.) Dubard. $(\mathrm{n}=7)$

Caule. Galha ovóide. Indutor: Manilkaramyia notabilis Maia 2001 (Cecidomyiidae). Localidades: CAR, JU e GUA. Referências: Bregonci et al. (2010), Maia (2001a, b) e Monteiro et al. (2004)

Caule. Galha globosa, verde, glabra. Indutor: Cecidomyiidae. Localidade: GUA. Referência: Bregonci et al. (2010).

Folha. Galha circular. Indutor: Cecidomyiidae. Localidades: IG, GRU, AC, CAR e JU. Referências: Maia (2001a), Maia \& Oliveira (2010), Monteiro et al. (2004) e Oliveira \& Maia (2005).

Folha. Galha tubular. Indutor: Asphondyliini (Cecidomyiidae).

Localidades: AC e JU. Referência: Monteiro et al. (1994, 2004).

Folha. Galha epidérmica. Indutor não determinado. Localidade: JU. Referência: Monteiro et al. (2004).

Folha. Galha redonda, verde, glabra. Indutor não determinado. Localidade: GUA. Referência: Bregonci et al. (2010).

Folha. Galha: enrolamento da borda, verde, glabro. Indutor não determinado. Localidade: GUA. Referência: Bregonci et al. (2010).

Pouteria caimito (R. \& P.) Radlk. var. laurifolia (Gomes) Baehni $(\mathrm{n}=1)$ 
Folha. Galha tubular. Indutor: Youngomyia pouteriae Maia 2001 (Cecidomyiidae); inquilino - Trotteria quadridentata Maia 2001 (Cecidomyiidae). Localidades: GRU, MAR e AC. Referências: Maia (2001c), Monteiro et al. (1994) e Oliveira \& Maia (2005).

Pouteria grandiflora (A. DC.) Baehni $(\mathrm{n}=1)$

Folha. Galha cônica, castanha, rígida e glabra. Indutor não determinado. Localidade: BER. Referência: Lima et al. (2000).

Pouteria venosa (Mart.) Baehni = Pouteria marginata $(\mathrm{n}=1)$

Folha. Galha ovóide, verde. Indutor: Lopesia singularis Maia, 2001 (Cecidomyiidae). Localidades: BER, MAR e AC. Referências: Monteiro et al. (1994), Maia (2001a) e Maia et al. (2008).

Pouteria psammophyla $(\mathrm{n}=1)$

Folha. Galha ovóide, verde. Indutor: Lopesia singularis Maia, 2001 (Cecidomyiidae). Localidades: GRU e MAR. Referências: Monteiro et al. (1994) e Oliveira \& Maia (2005).

$$
\text { Smilacaceae }(\mathrm{n}=9)
$$

Smilax quinquenervia Vell. $(\mathrm{n}=3)$

Nervura central. Galha: espessamento fusiforme, unilocular. Indutor: Cecidomyiidae. Localidade: BER. Referência: Maia et al. (2008).

Folha. Galha parenquimática, unilocular. Indutor: Cecidomyiidae. Localidade: BER. Referência: Maia et al. (2008).

Folha. Galha cônica. Indutor: Sternorrhyncha (Hemiptera). Localidade: BER. Referência: Maia et al. (2008).

Smilax rufescens Griseb $(\mathrm{n}=6)$

Folha. Galha circular. Indutor: Smilasioptera candelariae Möhn 1975 (Cecidomyiidae). Localidades: GRU, MAR, CAR e JU. Referências: Maia (2001a), Monteiro et al. (2004) e Oliveira \& Maia (2005).

Nervura foliar e pecíolo. Galha: espessamento fusiforme. Indutor: Cecidomyiidae. Localidades: GRU, MAR e CAR. Referências: Maia (2001a), Monteiro et al. (1994, 2004) e Oliveira \& Maia (2005).

Fruto. Larvas livres, Clinodiplosis sp. (Cecidomyiidae).

Localidade: MAR. Referência: Maia (2001a).

Folha. Galha triangular. Indutor: Hemiptera. Localidades: IG, MAR, AC e GUA. Referências: Bregonci et al. (2010), Maia \& Oliveira (2010) e Monteiro et al. (1994).

Folha. Galha epidérmica. Indutor não determinado. Localidade: JU. Referência: Monteiro et al. (2004).

Folha. Galha redonda, verde, glabra. Indutor não determinado. Localidade: GUA. Referência: Bregonci et al. (2010).

$$
\text { Solanaceae }(\mathrm{n}=12)
$$

Aureliana fasciculata (Vell.) Sendtn. $(\mathrm{n}=4)$

Caule. Galha: espessamento unilocular. Indutor: Asphondylia sp. (Cecidomyiidae). Localidade: BER. Referência: Maia et al. (2008).

Nervura central. Galha: espessamento fusiforme. Indutor: Clinodiplosis sp. (Cecidomyiidae). Predador: Lestodiplosis sp. (Cecidomyiidae). Localidade: BER. Referência: Maia et al. (2008).

Folha. Galha: dobramento da folha jovem. Indutor: Cecidomyiidae. Localidades: CAR e JU. Referências: Maia (2001a) e Monteiro et al. (2004).

Folha. Galha elíptica. Indutor: Cecidomyiinae. Localidade: CAR. Referência: Maia (2001a).
Aureliana glomuliflora Sendtn. $(\mathrm{n}=1)$

Nervura central. Galha: espessamento fusiforme. Indutor não determinado. Localidade: BER. Referência: Maia et al. (2008).

Cestrum laevigatum Schltdl. $(\mathrm{n}=2)$

Caule. Galha globosa, unilocular, lateral. Indutor não determinado. Localidade: BER. Referência: Maia et al. (2008).

Nervura central. Galha: espessamento fusiforme. Indutor não determinado. Localidade: BER. Referência: Maia et al. (2008).

Solanum affine Sendth $(\mathrm{n}=1)$

Folha. Galha globosa, amarela. Indutor: Cecidomyiinae. Localidade: MAR. Referência: Maia (2001a).

Solanum curvispinum Dunal $(\mathrm{n}=1)$

Folha. Galha globosa, amarela. Indutor: Cecidomyiidae.

Localidade: GRU. Referência: Oliveira \& Maia (2005).

Solanum inaequale Vell. $(\mathrm{n}=1)$

Folha. Galha circular, verde. Indutor: Cecidomyiinae. Localidades: CAR e JU. Referências: Maia (2001a) e Monteiro et al. (2004).

Solanum cf. pseudoquina A. St.-Hil. $(\mathrm{n}=1)$

Caule. Galha: espessamento fusiforme. Indutor não determinado. Localidade: BER. Referência: Maia et al. (2008).

Solanum aff.subscandens Vell. $(\mathrm{n}=1)$

Folha. Indutor: Cecidomyiidae. Localidade: MAR. Referência: Monteiro et al. (1994).

$$
\text { Styracaceae }(\mathrm{n}=1)
$$

Styrax glaber Sw. $(\mathrm{n}=1)$

Nervura foliar. Galha: espessamento fusiforme. Indutor não determinado. Localidade: BER. Referência: Maia et al. (2008). Theaceae $(\mathrm{n}=2)$

Gordonia fruticosa (Schrad.) H. Keng. $(\mathrm{n}=2)$

Gemas laterais e apicais. Galha ovóide, unilocular. Indutor: Clinodiplosis sp. (Cecidomyiidae). Localidade: BER. Referência: Maia et al. (2008).

Nervura foliar. Galha: espessamento fusiforme. Indutor: Neolasioptera sp. (Cecidomyiidae). Localidade: BER. Referência: Maia et al. (2008).

Thymelaeaceae $(\mathrm{n}=1)$

Daphnopsis racemosa Griseb $(\mathrm{n}=1)$

Gema. Galha globóide, verde, crassa e glabra. Indutor não determinado. Localidade: BER. Referência: Lima et al. (2000). Urticaceae $(\mathrm{n}=1)$

Coussapoa microcarpa (Schott) Rizzini $(\mathrm{n}=1)$

Caule. Galha: espessamento globoso. Indutor não determinado. Localidade: BER. Referência: Maia et al. (2008). Verbenaceae $(\mathrm{n}=3)$

Aegiphila sellowiana Cham. $(\mathrm{n}=1)$

Folha. Galha cilíndrica, verde, crassa e pilosa. Indutor não determinado. Localidade: BER. Referência: Lima et al.. (2000).

Lantana camara L. $(\mathrm{n}=1)$

Folha. Galha globosa, pilosa. Indutor: Schismatodiplosis lantanae Riibsaamen,1907 (Cecidomyiidae). Localidade: MAR. Referência: Maia (2001a) e Monteiro et al. (1994).

Lantana undulata Schrank $(\mathrm{n}=1)$ 
Folha. Galha globosa, pilosa, unilocular. Indutor: Clinodiplosis sp. (Cecidomyiidae). Localidade: BER. Referência: Maia et al. (2008).

\section{Discussão}

Os resultados encontrados para as restingas da região sudeste do Brasil corroboram apenas em parte o padrão indicado por Houard (1933) para a região Neotropical. Segundo esse autor, as cinco famílias botânicas com maior riqueza de galhas são: Fabaceae, Asteraceae, Melastomataceae, Myrtaceae e Solanaceae. A família Cecidomyiidae são os galhadores mais freqüentes, depois Hemiptera, Hymenoptera, e Lepidoptera ocorrendo principalmente em Melastomataceae e Anacardiaceae e induzindo galhas caulinares; e em quinto Coleoptera e, por fim, Thysanoptera.

Nas restingas da região sudeste do Brasil, as cinco famílias botânicas com maior riqueza de galhas são Myrtaceae, Asteraceae, Fabaceae, Melastomataceae e Lauraceae, ou seja, das cinco famílias citadas por Houard (op. cit.), quatro destacaram-se também no presente estudo, embora com algumas diferenças, discutidas a seguir:

As Myrtaceae foram apontadas como a família mais rica em número de galhas de insetos em restinga da região sudeste do Brasil, enquanto aparecem em quarto lugar no estudo de Houard (1933). As Asteraceae ocupam o segundo lugar em ambos os estudos. Já Fabaceae e Melastomataceae ocupam a terceira e quarta posição no presente estudo, diferindo dos dados de Houard (op. cit.), onde essas mesmas famílias ocupam o primeiro e terceiro lugar. As Lauraceae aparecem como a quinta família de planta com maior riqueza de galhas de insetos no presente estudo, e são citadas em nono lugar por Houard (1933). E as Solanaceae, não se destacam pela riqueza de galhas no presente estudo, enquanto que em Houard (op. cit.) aparecem em quinto lugar. Esses resultados estão relacionados com a diversidade das famílias botânicas. De acordo com Rizzini (1979), as Myrtaceae estão muito bem representadas nas restingas e contribuem significativamente para a caracterização de sua flora, sendo Eugenia Linnaeus o maior gênero em número de espécies. As famílias Asteraceae, Fabaceae, Melastomataceae e Lauraceae também são

Tabela 7. Distribuição do número de espécies vegetais por família de planta em diferentes localidades da região sudeste do Brasil. As informações para Bertioga (SP) foram retiradas de Martins et al. (2008); para Grumari (RJ): Argolo (2001); Maricá (RJ): Silva \& Oliveira (1989); Jurubatiba (RJ): Araujo et al. (1998); e Guarapari (ES): Assis et al. (2004).

Table 7. Distribution of the number of plant species by plant families in restingas of the southeastern region of Brazil. Data on Bertioga (SP) were obtained from Martins et al. (2008); Grumari (RJ): Argolo (2001); Maricá (RJ): Silva \& Oliveira (1989); Jurubatiba (RJ): Araujo et al. (1998); and Guarapari (ES): Assis et al. (2004).

\begin{tabular}{|c|c|c|c|c|c|}
\hline \multirow{2}{*}{ Famílias de Planta } & \multicolumn{5}{|c|}{ Número de espécies } \\
\hline & Bertioga, SP & Grumari, RJ & Maricá, RJ & Jurubatiba, RJ & Guarapari, ES \\
\hline ACANTHACEAE & 8 & 1 & 5 & 1 & 0 \\
\hline ALISMATACEAE & 0 & 0 & 1 & 1 & 0 \\
\hline ALSTROEMERIACEAE & 1 & 0 & 0 & 0 & 0 \\
\hline AMARANTHACEAE & 2 & 2 & 3 & 1 & 0 \\
\hline AMARYLLIDACEAE & 1 & 1 & 2 & 0 & 1 \\
\hline ANACARDIACEAE & 2 & 2 & 3 & 2 & 1 \\
\hline ANNONACEAE & 5 & 1 & 2 & 4 & 3 \\
\hline APIACEAE & 1 & 1 & 2 & 0 & 0 \\
\hline APOCYNACEAE & 11 & 4 & 10 & 2 & 3 \\
\hline AQUIFOLIACEAE & 3 & 0 & 1 & 2 & 0 \\
\hline ARACEAE & 14 & 3 & 5 & 0 & 4 \\
\hline ARALIACEAE & 5 & 0 & 0 & 0 & 0 \\
\hline ARECACEAE & 9 & 1 & 4 & 4 & 3 \\
\hline ARISTOLOCHIACEAE & 0 & 0 & 1 & 0 & 0 \\
\hline ASCLEPIADACEAE & 0 & 0 & 9 & 3 & 0 \\
\hline ASTERACEAE & 35 & 5 & 21 & 3 & 0 \\
\hline BEGONIACEAE & 4 & 0 & 9 & 0 & 0 \\
\hline BIGNONIACEAE & 9 & 5 & 11 & 1 & 1 \\
\hline BLECHNACEAE & 0 & 0 & 0 & 1 & 0 \\
\hline BOMBACACEAE & 0 & 1 & 1 & 2 & 2 \\
\hline BORAGINACEAE & 3 & 2 & 3 & 0 & 0 \\
\hline BRASSICACEAE & 1 & 0 & 0 & 0 & 0 \\
\hline BROMELIACEAE & 36 & 14 & 14 & 6 & 14 \\
\hline BURMANNIACEAE & 2 & 0 & 1 & 0 & 0 \\
\hline BURSERACEAE & 0 & 0 & 2 & 2 & 1 \\
\hline CACTACEAE & 4 & 4 & 12 & 4 & 3 \\
\hline CALYCERACEAE & 1 & 1 & 1 & 0 & 0 \\
\hline CAMPANULACEAE & 1 & 0 & 0 & 0 & 0 \\
\hline CANNABACEAE & 1 & 0 & 0 & 0 & 0 \\
\hline CAPPARIDACEAE & 0 & 2 & 5 & 2 & 3 \\
\hline CECROPIACEAE & 0 & 1 & 0 & 0 & 0 \\
\hline
\end{tabular}


Tabela 7. Continuação...

\begin{tabular}{|c|c|c|c|c|c|}
\hline \multirow{2}{*}{ Famílias de Planta } & \multicolumn{5}{|c|}{ Número de espécies } \\
\hline & Bertioga, SP & Grumari, RJ & Maricá, RJ & Jurubatiba, RJ & Guarapari, ES \\
\hline CELASTRACEAE & 6 & 1 & 1 & 1 & 1 \\
\hline CHLORANTHACEAE & 1 & 0 & 0 & 0 & 0 \\
\hline CHRYSOBALANACEAE & 5 & 2 & 1 & 1 & 0 \\
\hline CLETHRACEAE & 1 & 0 & 0 & 0 & 0 \\
\hline CLUSIACEAE & 3 & 2 & 5 & 6 & 4 \\
\hline COMBRETACEAE & 2 & 0 & 1 & 0 & 1 \\
\hline COMMELINACEAE & 3 & 1 & 2 & 1 & 1 \\
\hline CONNARACEAE & 1 & 1 & 0 & 0 & 0 \\
\hline CONVOLVULACEAE & 7 & 2 & 5 & 2 & 0 \\
\hline COSTACEAE & 2 & 0 & 0 & & 1 \\
\hline CUCURBITACEAE & 4 & 0 & 0 & 0 & 0 \\
\hline CUNONIACEAE & 1 & 0 & 0 & 0 & 0 \\
\hline CYCLANTHACEAE & 1 & 0 & 0 & 1 & 0 \\
\hline CYPERACEAE & 23 & 1 & 9 & 8 & 0 \\
\hline DENNSTAEDTIACEAE & 0 & 0 & 0 & 2 & 0 \\
\hline DICHAPETALACEAE & 0 & 0 & 0 & 1 & 0 \\
\hline DILLENIACEAE & 2 & 0 & 1 & 0 & 0 \\
\hline DIOSCOREACEAE & 3 & 2 & 1 & 0 & 0 \\
\hline DROSERACEAE & 1 & 1 & 0 & 1 & 0 \\
\hline EBENACEAE & 1 & 0 & 1 & 1 & 1 \\
\hline ELAEOCARPACEAE & 1 & 0 & 0 & 1 & 0 \\
\hline ERICACEAE & 1 & 0 & 2 & 2 & 0 \\
\hline ERIOCAULACEAE & 2 & 0 & 2 & 1 & 0 \\
\hline ERYTHROXYLACEAE & 2 & 1 & 4 & 2 & 3 \\
\hline EUPHORBIACEAE & 11 & 3 & 21 & 5 & 1 \\
\hline FABACEAE & 33 & 05 & 28 & 10 & 5 \\
\hline FLACOURTIACEAE & 1 & 1 & 0 & 0 & 0 \\
\hline GENTIANACEAE & 2 & 4 & 2 & 1 & 0 \\
\hline GESNERIACEAE & 5 & 0 & 1 & 0 & 0 \\
\hline HALORAGACEAE & 0 & 0 & 1 & 1 & 0 \\
\hline HELICONIACEAE & 2 & 0 & 0 & 0 & 0 \\
\hline HIPPOCRATEACEAE & 0 & 1 & 0 & 0 & 0 \\
\hline HUMIRIACEAE & 1 & 0 & 1 & 1 & 0 \\
\hline HYPOXIDACEAE & 1 & 0 & 0 & 0 & 0 \\
\hline IRIDACEAE & 2 & 0 & 1 & 0 & 1 \\
\hline JUNCACEAE & 2 & 0 & 0 & 0 & 0 \\
\hline LAMIACEAE & 9 & 0 & 1 & 0 & 0 \\
\hline LAURACEAE & 14 & 0 & 3 & 3 & 7 \\
\hline LENTIBULARIACEAE & 3 & 0 & 2 & 5 & 0 \\
\hline LOGANIACEAE & 2 & 0 & 0 & 0 & 1 \\
\hline LORANTHACEAE & 1 & 0 & 5 & 0 & 0 \\
\hline LYCOPODIACEAE & 0 & 0 & 1 & 0 & 0 \\
\hline LYTHRACEAE & 0 & 0 & 1 & 1 & 0 \\
\hline MALPIGHIACEAE & 10 & 5 & 10 & 3 & 2 \\
\hline MALVACEAE & 4 & 1 & 3 & 1 & 2 \\
\hline MARANTACEAE & 4 & 0 & 1 & 1 & 1 \\
\hline MARCGRAVIACEAE & 2 & 0 & 1 & 0 & 0 \\
\hline MELASTOMATACEAE & 19 & 0 & 8 & 4 & 2 \\
\hline MELIACEAE & 3 & 1 & 0 & 1 & 3 \\
\hline MENISPERMACEAE & 0 & 2 & 0 & 1 & 0 \\
\hline MENYANTHACEAE & 1 & 0 & 1 & 1 & 0 \\
\hline MOLLUGINACEAE & 0 & 0 & 1 & 0 & 0 \\
\hline MONIMIACEAE & 2 & 0 & 0 & 1 & 1 \\
\hline MORACEAE & 7 & 0 & 6 & 3 & 5 \\
\hline MYRSINACEAE & 7 & 1 & 2 & 3 & 2 \\
\hline MYRTACEAE & 38 & 6 & 14 & 15 & 25 \\
\hline
\end{tabular}


Maia, V.C.

Tabela 7. Continuação...

\begin{tabular}{|c|c|c|c|c|c|}
\hline \multirow{2}{*}{ Famílias de Planta } & \multicolumn{5}{|c|}{ Número de espécies } \\
\hline & Bertioga, SP & Grumari, RJ & Maricá, RJ & Jurubatiba, RJ & Guarapari, ES \\
\hline NAJDACEAE & 0 & 0 & 0 & 1 & 0 \\
\hline NYCTAGINACEAE & 2 & 2 & 4 & 1 & 4 \\
\hline NYMPHAEACEAE & 0 & 0 & 0 & 2 & 0 \\
\hline OCHNACEAE & 2 & 1 & 1 & 2 & 2 \\
\hline OLACACEAE & 1 & 1 & 5 & 1 & 3 \\
\hline ONAGRACEAE & 1 & 0 & 3 & 0 & 0 \\
\hline ORCHIDACEAE & 47 & 11 & 15 & 1 & 13 \\
\hline PASSIFLORACEAE & 3 & 1 & 4 & 2 & 0 \\
\hline PENTAPHYLLACACEAE & 1 & 0 & 0 & 0 & 0 \\
\hline PHYLLANTHACEAE & 2 & 0 & 0 & 0 & 0 \\
\hline PHYTOLACCACEAE & 1 & 0 & 2 & 1 & 0 \\
\hline PICRAMNIACEAE & 1 & 0 & 0 & 0 & 0 \\
\hline PIPERACEAE & 9 & 2 & 4 & 0 & 4 \\
\hline PLANTAGINACEAE & 6 & 0 & 0 & 0 & 0 \\
\hline PLUMBAGINACEAE & 0 & 0 & 1 & 0 & 0 \\
\hline POACEAE & 20 & 4 & 8 & 7 & 0 \\
\hline PODOCARPACEAE & 1 & 0 & 0 & 0 & 0 \\
\hline POLYGALACEAE & 3 & 2 & 0 & 0 & 0 \\
\hline POLYGONACEAE & 3 & 2 & 5 & 2 & 1 \\
\hline POLYPODIACEAE & 0 & 0 & 6 & 0 & 0 \\
\hline PONTEDERIACEAE & 0 & 0 & 0 & 1 & 0 \\
\hline PORTULACACEAE & 1 & 0 & 0 & 0 & 0 \\
\hline POTAMOGETONACEAE & 0 & 0 & 0 & 1 & 0 \\
\hline PROTEACEAE & 1 & 0 & 0 & 0 & 0 \\
\hline RHAMNACEAE & 1 & 1 & 2 & 2 & 0 \\
\hline ROSACEAE & 1 & 0 & 0 & 0 & 0 \\
\hline RUBIACEAE & 34 & 3 & 15 & 4 & 2 \\
\hline RUTACEAE & 1 & 0 & 2 & 1 & 0 \\
\hline SALICACEAE & 2 & 0 & 0 & 0 & 0 \\
\hline SANTALACEAE & 3 & 0 & 0 & 0 & 0 \\
\hline SAPINDACEAE & 8 & 4 & 8 & 3 & 5 \\
\hline SAPOTACEAE & 4 & 3 & 5 & 2 & 10 \\
\hline SCROPHULARICEAE & 0 & 0 & 1 & 0 & 0 \\
\hline SIMAROUBACEAE & 0 & 0 & 0 & 1 & 2 \\
\hline SMILACACEAE & 2 & 1 & 2 & 2 & 1 \\
\hline SOLANACEAE & 15 & 2 & 7 & 0 & 3 \\
\hline SPHAGNACEAE & 0 & 0 & 0 & 1 & 0 \\
\hline STERCULIACEAE & 0 & 0 & 0 & 1 & 0 \\
\hline STYRACACEAE & 1 & 0 & 0 & 0 & 0 \\
\hline THEACEAE & 1 & 0 & 0 & 3 & 0 \\
\hline THEOPHRASTACEAE & 0 & 0 & 0 & 1 & 1 \\
\hline THYMELAEACEAE & 1 & 0 & 0 & 0 & 1 \\
\hline THYРНACEAE & 0 & 0 & 1 & 1 & 0 \\
\hline TRIGONIACEAE & 0 & 1 & 0 & 0 & 0 \\
\hline TURNERACEAE & 0 & 0 & 0 & 1 & 0 \\
\hline URTICACEAE & 8 & 0 & 0 & 0 & 0 \\
\hline VERBENACEAE & 1 & 0 & 4 & 1 & 0 \\
\hline VIOLACEAE & 0 & 0 & 1 & 0 & 0 \\
\hline VISCACEAE & 0 & 1 & 0 & 0 & 0 \\
\hline VITACEAE & 2 & 0 & 1 & 0 & 1 \\
\hline VOCHYSIACEAE & 0 & 0 & 0 & 1 & 0 \\
\hline XYRIDACEAE & 2 & 0 & 2 & 1 & 0 \\
\hline ZINGIBERACEAE & 1 & 0 & 0 & 0 & 0 \\
\hline
\end{tabular}


famílias bem representadas nesse ecossistema (Tabela 7). Portanto, pode-se afirmar que a riqueza de galhas de insetos em restingas da região sudeste do Brasil está relacionada com a riqueza das espécies das famílias de plantas.

As ordens de insetos galhadores encontradas nas restingas são as mesmas que constam em Houard (1933), porém ocupando diferentes posições em termos de diversidade, exceto por Diptera, que aparecem como o principal grupo em ambos os estudos. Em restingas, Lepidoptera ocupa o segundo lugar, Hemiptera o terceiro, Coleoptera o quarto, Thysanoptera o quinto e em último, Hymenoptera. Em Houard (op. cit.), Hemiptera aparece em segundo lugar, Hymenoptera em terceiro, Lepidoptera em quarto, Coleoptera em quinto e Thysanoptera em sexto.

Em ambos os estudos, Cecidomyiidae e Lepidoptera mostraram preferência pela indução de galhas em folhas e caules, respectivamente. Mas a ocorrência de galhas de Lepidoptera principalmente em Melastomataceae e Anacardiaceae não foi confirmada: de 15 morfotipos de galhas, três ocorreram na primeira e apenas um na segunda família de planta citada. Três morfotipos (o número máximo de galhas de Lepidoptera encontradas em uma mesma família botânica no presente estudo) também ocorreram em Myrsinaceae.

A maior incidência de galhas em folhas é um padrão que se observa em todas as regiões zoogeográficas do mundo (Felt 1940), provalmente pelas folhas representarem um recurso mais abundante e renovável.

\section{Conclusão}

As restingas da região sudeste do Brasil possuem uma riqueza de 479 morfotipos de galhas de insetos distribuídos em 60 famílias, 131 gêneros e 229 espécies de plantas. As famílias de planta com maior riqueza de galhas são bem representadas e diversificadas em restingas (Myrtaceae, Asteraceae e Fabaceae). O mesmo pode-se afirmar em relação aos gêneros (Eugenia L., Mikania Willd. e Myrcia DC. Ex Guill). Guapira opposita (Vell.) Reitz (Nyctaginaceae), Mikania cf. biformis DC. (Asteraceae) e Eugenia umbelliflora O. Berg (Myrtaceae) são as espécies super-hospedeiras. As galhas ocorreram em órgãos vegetativos e reprodutivos, mas predominando nas folhas. Os indutores distribuíram-se em seis ordens de insetos: Diptera, Lepidoptera, Hemiptera, Coleoptera, Thysanoptera e Hymenoptera, com destaque para Cecidomyiidae (Diptera) como o principal grupo galhador, os quais mostraram uma forte preferência por folhas, enquanto Lepidoptera por caule.

O conhecimento taxonômico das espécies galhadoras é incipiente. Apenas 21\% do total de morfotipos de galhas registrados em restingas da região sudeste do Brasil têm a espécie galhadora identificada. Isto se deve em parte à carência de taxonomistas atuando neste ecossistema, e no caso dos Cecidomyiidae, à dificuldade de obtenção de espécimes imaturos (larvas de terceiro instar e pupas) e adultos de ambos os sexos, necessários para a identificação das espécies.

A obtenção de representantes de cada fase do ciclo de vida e de machos e fêmeas envolve a criação dos galhadores em campo ou em laboratório, grandemente dificultada em função das altas taxas de parasitismo observadas em restingas, do desconhecimento da biologia das espécies, do ressecamento do órgão galhado (depois que removido da planta hospedeira) e de perda de material em função do crescimento de fungos nos potes de criação. Acrescente-se a esta dificuldade, a inexistência de chaves atualizadas de gêneros e de espécies, e a escassez de coleções de referências para a família.

O número de espécies e gêneros novos a serem descritos é muito grande, e ainda há muitas áreas não investigadas que representam lacunas de informação na diversidade e distribuição das espécies.

\section{Agradecimentos}

Ao CNPq pelo suporte financeiro (Proc. 300237/2010-3).

\section{Referências Bibliográficas}

ANGELO, A. \& MAIA, V.C. 1999. Dasineura gigantea n. sp. (Diptera, Cecidomyiidae) associada com Psidium cattleyanum (Myrtaceae) no Brasil. Rev. Bras. Zool. 16(1):191-195. http://dx.doi.org/10.1590/S010181751999000100014

ARAUJO, D.S.D. \& MACIEL, N.C. 1998. Restingas fluminensis: biodiversidade e preservação. Boletim FBCN 25:27-51.

ARAUJO, D.S.D., SCARANO, F.R., SÁ, C.F., KURTZ, B.C., ZALUAR, H.L.T., MONTEZUMA, R.C.M. \& OLIVEIRA, R.C. 1998. Comunidades vegetais do Parque Nacional da Restinga de Jurubatiba. In Ecologia das lagoas costeiras do Parque Nacional da Restinga de Jurubatiba e do Município de Macaé (RJ) (F.A. Esteves, ed.). Universidade Federal do Rio de Janeiro, p.39-55.

ARGOLO, A.M. 2001. Levantamento florístico, caracterização fisionômica e comparação da restinga de Grumari, RJ, com outras restingas do Estado do Rio de Janeiro. Dissertação de Mestrado, Universidade Federal do Rio de Janeiro, Rio de Janeiro, 62p.

ASSIS, A.M., THOMAZ, L.D. \& PEREIRA, O.J. 2004. Florística de um trecho de floresta de restinga no município de Guarapari, Espírito Santo, Brasil. Acta Bot. Bras. 18(1):191-201. http://dx.doi.org/10.1590/S010233062004000100016

BREGONCI, J.M., POLYCARPO, P.V. \& MAIA, V.C. 2010. Galhas de insetos do Parque Estadual Paulo César Vinha (Guarapari, ES, Brasil). Biota Neotrop. 10(1): http://www.biotaneotropica.org.br/v10n1/en/abst ract?inventory+bn01410012010

BREMER, K. 1994. Asteraceae: Cladisct and Classification. Timber Press Inc., Oregon.

COURI, M.S. \& MAIA, V.C. 1992. Considerações sobre Pisphondylia Mohn, 1960 (Diptera, Cecidomyiidae, Asphondyliidi) com descrição de uma espécie nova para o Brasil. Rev. Bras. Entomol. 36(4):729-730.

FELT, E.P. 1940. Plant galls and gall makers. Ithaca, New York, 364p.

GAGNÉ, R.J. 2010. Update for a catalog of The Cecidomyiidae (Diptera) of the world. http://www.ars.usda.gov/SP2UserFiles/Place/12754100/ Gagne_2010_World_Catalog_Cecidomyidae.pdf (último acesso em 08/2012).

GOVAERTS, R.M., SOBRAL, M., ASHTON, P., BARRIE, F., HOLST, B.K., LANDRUM, L.L., MATSUMOTO, K., MAZINE, F.F., LUGHADHA, E.N., PROENÇA, C., SOARES-SILVA, L.H., WILSON, P.G. \& LUCAS, E. 2008. World checklist of Myrtaceae. Royal Botanic Gardens, Kew, 455p. http://www.kew.org/wcsp/ (último acesso em 10/01/2011).

HOUARD, E. 1933. Les zoocécidies dês plantes de l'Amérique Du Sud et de l'Amérique Central. Hermann et Cie, Paris, 549p.

LIMA, E.S., MAGENTA, M.A.G., KRAUS, J.E., VECHI, C. \& MARTINS, S.E. 2000. Levantamento preliminar de galhas entomógenas ocorrentes em plantas das restingas de Beertioga (SP). Anais do V Simpósio de Ecossistemas Brasileiros: Conservação. III. ACIESP 109:39-46.

MADEIRA, J.A., MAIA, V.C. \& MONTEIRO, R.F. 2002. Gall makers (Cecidomyiidae: Diptera) on Calophyllum brasiliense Camb. (Clusiaceae): descriptions and biology. Arq. Mus. Nac. 61(1):31-48.

MAIA, V.C. 1993a. Descrição de duas espécies novas de Cecidomyiidae (Diptera) associadas a Eugenia spp. (Myrtaceae). Rev. Bras. Entomol. 37(4):717-721.

MAIA, V.C. 1993b. Considerações sobre Proasphondylia Felt, 1915 (Diptera, Cecidomyiidae, Asphondyliidi) com descrição de duas espécies novas associadas com Guapira opposita (Velloso) Reitz. (Nyctaginaceae). Rev. Bras. Zool. 10(2):215-218. http://dx.doi.org/10.1590/S010181751993000200003 
MAIA, V.C. 1993c. Considerações sobre Stephomyia Tavares, 1916 (Diptera, Cecidomyiidae, Asphondyliidi) com descrição de quatro espécies novas associadas com Eugenia L. e Neomitranthes (DC) Legr. (Myrtaceae). Rev. Bras. Zool. 10(3):521-530. http://dx.doi.org/10.1590/S010181751993000300019

MAIA, V.C. 1993d. Três espécies novas de Dasineura Rondani (Diptera, Cecidomyiidae) associadas a Myrtaceae na Restinga da Barra de Maricá, Rio de Janeiro. Rev. Bras. Zool. 12(4):1001-1008. http://dx.doi. org/10.1590/S0101-81751995000400027

MAIA, V.C. 1993e. Uma nova espécie de Clinodiplosis Kieffer (Diptera, Cecidomyiidae) associada com Melissa officinalis Linnaeus (Labiatae) no Brasil. Rev. Bras. Zool. 10 (4):695-697. http://dx.doi.org/10.1590/ S0101-81751993000400014

MAIA, V.C. 1994. Myrciariamyia bivalva, gen. N. e sp. n. (Diptera, Cecidomyiidae, Oligotrophini) associado com Myrciaria floribunda (Camb.) Legr. (Myrtaceae) no Brasil. Rev. Bras. Zool. 11(4):635-639. http://dx.doi.org/10.1590/S0101-81751994000400007

MAIA, V.C. 1995. Dois gêneros novos de Cecidomyiidae (Diptera) associados a Myrtaceae, na Restinga da Barra de Maricá, Rio de Janeiro, Brasil. Rev. Bras. Zool. 12(3):567-574. http://dx.doi.org/10.1590/S010181751995000300012

MAIA, V.C. 1996a. Cordiamyia globosa, n. gen. E n. sp. (Diptera, Cecidomyiidae) associado com Cordia verbenacea (Boraginaceae), na Restinga da Barra de Maricá (R.J.). Rev. Bras. Zool. 13(3):579-583. http://dx.doi.org/10.1590/S0101-81751996000300006

MAIA, V.C. 1996b. Clusiamyia nitida, n. gen. En. sp (Diptera, Cecidomyiidae) associado com Clusia lanceolata Camb. (Clusiaceae) no Brasil. Rev. Bras. Zool. 13 (4):829-832. http://dx.doi.org/10.1590/S010181751996000400003

MAIA, V.C. 1999. Descrição de imaturos de quatro espécies de Asphondyliini neotropicais e nota taxonômica sobre Asphondylia maytenuse Maia \& Couri (Diptera, Cecidomyiidae). Rev. Bras. Zool. 16(3):775-778. http:// dx.doi.org/10.1590/S0101-81751999000300014

MAIA, V.C. 2001a. The gall midges (Diptera, Cecidomyiidae) from three restingas of Rio de Janeiro State, Brazil. Rev. Bras. Zool. 18(2):583-629. http://dx.doi.org/10.1590/S0101-81752001000200028

MAIA, V.C. 2001b. New genera and species of gall midges (Diptera, Cecidomyiidae) from three restingas of Rio de Janeiro State, Brazil. Rev. Bras. Zool., 18(Supl. 1):1-32.

MAIA, V.C. 2001c. Two new species of gall midges (Diptera, Cecidomyiidae) associated with Pouteria caimito var.laurifolia (Sapotaceae) in Brazil. Studia Dipt. 8(1):103-110.

MAIA, V.C. 2004. Description of a new species of Bruggmannia Tavares (Diptera, Cecidomyiidae) associated with Guapira opposita (Vell.) Reitz. (Nyctaginaceae) from Brazil. Rev. Bras. Zool. 21(4):761-764. http:// dx.doi.org/10.1590/S0101-81752004000400005

MAIA, V.C. 2005. Clinodiplosis costai, a new galler species (Diptera, Cecidomyiidae) associated with Paullinia weinmanniaefolia Mart. (Sapindaceae). Rev. Bras. Zool. 22(3):676-679. http://dx.doi.org/10.1590/ S0101-81752005000300024

MAIA, V.C. 2006. Galls of Hemiptera, Lepidoptera and Thysanoptera from Central and South America. Publ. Avul. Mus. Nac. 110:3-22.

MAIA, V.C. 2007. New genera and species of gall midges (Diptera, Cecidomyiidae) associated with Guarea macrophylla (Meliaceae). Rev. Bras. Zool. 24(3):449-456. http://dx.doi.org/10.1590/S010181752007000200024

MAIA, V.C. 2010. A new species of Dasineura Rondani, 1840 (Diptera, Cecidomyiidae) associated with Byrsonima sericea (Malpighiaceae). Rev. Bras. Bioc. 8(4):377-380

MAIA, V.C. \&ARAÚJO, W.S. 2009. Uma nova espécie de Schizomyia (Diptera, Cecidomyiidae) indutora de galhas nos botões florais de Jacquemontia holosericea (Convolvulaceae). Rev. Bras. Entomol. 53:356-360. http:// dx.doi.org/10.1590/S0085-56262009000300008
MAIA, V.C. \& COURI, M.S. 1993. Descrição de três espécies de Bruggmannia Tavares, 1915 (Diptera, Cecidomyiidae, Asphondyliidi) do Brasil, associadas com Guapira opposita (Nyctaginaceae). Rev. Bras. Biol. 53(2):209-215.

MAIA, V.C. \& FERNANDES, S.P.C. 2011. Two new species of gall midges (Diptera, Cecidomyiidae) associated with Erythroxylum ovalifolium Peyr. (Erythroxylaceae) from the Barra de Maricá restinga, Maricá, Rio de Janeiro, Brazil. Braz. J. Biol. 71(2):521-526. PMid:21755172. http:// dx.doi.org/10.1590/S1519-69842011000300024

MAIA, V.C. \& FONSECA, K.F. 2011. Burseramyia braziliensis, a new species of gall midge (Diptera, Cecidomyiidae, Asphondyliini) associated with Swartzia langsdorffii Raddi (Fabaceae). Biota Neotrop. 11(4):55-57. http://dx.doi.org/10.1590/S1676-06032011000400004

MAIA, V.C. \& OLIVEIRA, J.C. 2004. Coleoptera associated with galls from South America with new records. Arq. Mus. Nac. 62 (2):179-184.

MAIA, V.C. \& OLIVEIRA, J.C. 2010. Galhas de insetos da Reserva Biológica Estadual da Praia do Sul (Ilha Grande, Angra dos Reis, RJ) Biota Neotrop. 10(4):227-238. http://dx.doi.org/10.1590/S167606032010000400028

MAIA, V.C. \& OLIVEIRA, U.P. 2007. Uma nova espécie de Cecidomyiidae (Diptera) associada com Sebastiania glandulosa (Euphorbiaceae). Iheringia. Série Zool. 97:97-101.

MAIA, V.C. \& SANTOS, M.G. 2011. A new genus and species of gall midge (Diptera, Cecidomyiidae) associated with Microgramma vacciniifolia (Langsd. \& Fisch.) Copel. (Polypodiaceae) from Brazil. Rev. Bras. Entomol. 55(1):40-44. http://dx.doi.org/10.1590/S008556262011000100008

MAIA, V.C. \& SILVA, S.H.A. 2011. Representatividade do gênero Lopesia Rübsaamen (Diptera, Cecidomyiidae) no Brasil. Pap. Avulsos Zool. 51(23):359-365.

MAIA, V.C., AZEVEDO, M.A.P. \& COURI, M.S. 2002a. New contribution to the knowledge of the gall midges (Diptera, Cecidomyiidae) from the restinga of Barra de Maricá (Rio de Janeiro, Brazil). Studia Dipt. 9(2):447-452.

MAIA, V.C., CONSTANTINO, P.A.L. \& MONTEIRO, R.F. 2005. New gall midges (Diptera, Cecidomyiidae) associated with two species of Eugenia (Myrtaceae). Rev. bras. Entomol. 49(3):347-352.

MAIA, V.C., COURI, M.S. \& MONTEIRO, R.F. 1992. Sobre seis espécies de Asphondylia Loew, 1850 do Brasil (Diptera, Cecidomyiidae). Rev. bras. Entomol. 36(3):653-661.

MAIA, V.C., MAGENTA, M.A.G. \& MARTINS, S.E. 2008. Ocorrência e caracterização de galhas de insetos em áreas de restinga de Bertioga (São Paulo, Brasil). Biota Neotrop. 8(1): http:/www.biotaneotropica.org.br/ v8n1/ (último acesso em 22/12/2010).

MAIA, V.C., MENDONÇA JÚNIOR, M. \& ROMANOVSKY, H. 1996. Eugeniamyia dispar, n. gen. and n. sp (Diptera, Cecidomyiidae, Lasiopteridi) associated with Eugenia uniflora L. (Myrtaceae) in Brazil. Rev. Bras. Zool. 13(4):1087-1090.

MAIA, V.C., MONTEIRO, R.F. \& NARAHARA, K. 2002b. Two new species of gall midges (Diptera, Cecidomyiidae) associated with Protium icicariba (Burseraceae) in Brazil. Studia Dipt. 9(1):171-178.

MARTINS, S.E., ROSSI, L., SAMPAIO, P.S.P. \& MAGENTA, M.A.G. 2008. Caracterização florística de comunidades vegetais de restinga em Bertioga, SP, Brasil Acta Bot. Bras. 22(1):249-274.

MONTEIRO, R.F., FERRAZ, F.F.F., MAIA, V.C. \& AZEVEDO, M.A.P. 1994. Galhas entomógenas em restingas: uma abordagem preliminar. An. ACIESP 3(87):210-220.

MONTEIRO, R.F., ODA, R.A.M., NARAHARA, K.L. \& CONSTANTINO, P.A.L. 2004. Galhas: Diversidade, Especificidade e Distribuição. In Pesquisa de Longa Duração na Restinga de Jurubatiba: Ecologia, História Natural e Conservação (C.F.D. Rocha, F.A. Esteves \& F.R. Scarano, orgs.). RiMa Editora, São Carlos, p.127-141. 
NARAHARA, K., MAIA, V.C. \& MONTEIRO, R.F. 2004. Two new species of gall midges (Diptera, Cecidomyiidae) associated with Protium heptaphyllum (Aubl.) Marchand (Burseraceae) in Brazil. Rev. Bras. Entomol. 48(4):485-490. http://dx.doi.org/10.1590/S008556262004000400010

NOVO-GUEDES, R. \& MAIA, V.C. 2008. Gall midges (Diptera, Cecidomyiidae) associated with Heteropteris nitida DC. (Malpighiaceae). Arq. Mus. Nac. 66:359-362.

OLIVEIRA, J.C. \& MAIA, V.C. 2005. Ocorrência e caracterização de galhas de insetos na restinga de Grumari (Rio de Janeiro, RJ, Brasil). Arq. Mus. Nac. 63(4):669-676.

OLIVEIRA, U.P. \& MAIA, V.C. 2008. A new species of gall midge (Diptera, Cecidomyiidae) associated with Sebastiania glandulosa (Euphorbiaceae). Arq. Mus. Nac. 66:355-358.

OLIVEIRA, R.N., DIAS, I.J.M. \& CÂMARA, C.A.G. 2005. Estudo comparativo do óleo essencial de Eugenia punicifolia (HBK) DC. de diferentes localidades de Pernambuco. Rev. Bras. Pharmacogn. 15(1):39-43.

RIZZINI, C.T. 1979. Tratado de Fotogeografia do Brasil. Hucitec, São Paulo, v.2, $54 \mathrm{p}$.
RODRIGUES, A.R. \& MAIA, V.C. 2010. Duas novas espécies de Lopesia Rübsaamen (Diptera, Cecidomyiidae) do Brasil, com chave para as espécies. Biota Neotrop.10:1-15. http://dx.doi.org/10.1590/S167606032010000100008

SANTOS, B.O. \& MAIA, V.C. 2008. Uma nova espécie de Cecidomyiidae (Diptera) associada com Stylosanthes guianensis (Fabaceae). Arq. Mus. Nac. 66:485-489.

SILVA, J.G. \& OLIVEIRA, A.S. 1989. A vegetação de restinga no município de Maricá - R.J. Acta Bot. Bras. 3(2):253-272. http://dx.doi.org/10.1590/ S0102-33061989000300021

SOUSA, L.I. \& MAIA, V.C. 2007. A new species of Schizomyia (Diptera, Cecidomyiidae, Asphondyliini) associated with Tetrapterys phlomoides (Malpighiaceae). Iheringia. Série Zool. 97:311-313. http://dx.doi. org/10.1590/S0073-47212007000300021

TOMA, T.S.P. \& MAIA, V.C. 2012. Representatividade do gênero Clinodiplosis Kieffer (Diptera, Cecidomyiidae) no Brasil. Pap. Avulsos Zool. 52(20):223-231.

VICECONTE, K.S.M. \& MAIA, V.C. 2009. Novo gênero e nova espécie de Diptera, Cecidomyiidae, associada com Psittacanthus dichrous (Loranthaceae). Arq. Mus. Nac. 67:35-40.

Recebido em 21/06/2011

Versão reformulada recebida em 15/08/2012

Publicado em 06/02/2013 